Chapter 5

\title{
Classification of Health Care Functions (ICHA-HC)
}




\section{Introduction}

Within the health accounting framework, the underlying principle may be formulated as "what is consumed has been provided and financed". Clearly, there is no one-to-one relationship between health care functions and the provision and financing categories. The same type of health care goods and services can be consumed from different types of providers and at the same time purchased using various types of financing schemes. But to achieve the tri-axial perspective (consumption-provisionfinancing), the starting point is to measure consumption (see Chapter 4), which in a health functional approach describes the direct consumption by the population according to the type of health purpose. The boundaries of health care are set based on this consumption purpose. It is therefore important to have a clear understanding of what consumption with a health purpose is, and which are the relevant categories to be identified.

The functional classification in the health accounting framework focuses on the estimation of current spending and involves the contact of the population with the health system for the purpose of satisfying health needs. Therefore, investment is not included here but treated separately in Chapter 11 "Capital formation in health systems".

The conceptual and taxonomic exercise to generate the functional classification, as with other classifications, must take account of feasibility constraints. Experience has shown that the compilation can be limited by the nature of national health statistical systems, which seldom correspond to a classification based on health purpose. Hence, what is to be classified can differ according to both the data available and the ability to implement an accounting framework.

This chapter continues with a discussion of the concept of "function" and the uses of a function-based classification within the SHA framework. A summary of the main changes from SHA 1.0 is also provided. The full classification of health care functions is then presented, together with definitions and examples, and those areas requiring further development to strengthen accountability are identified.

\section{Health care consumption by purpose}

In an accounting sense, a "function" relates "to the type of need a transaction or group of transactions aims to satisfy or the kind of objective pursued". Transactions on the expenditure side deal with the question "for what purpose?" (SNA 2008, 2.42).

The accounting process involves the identification of the transactions and the resources involved in the process of satisfying health needs. ${ }^{1}$ In summary, the classification of functions refers to groups of health care goods and services consumed by final users (i.e. households ${ }^{2}$ ) with a specific health purpose (see Chapter 4). 
Health care is generally consumed as an integrated service package. In fact, a contact with the health system normally includes a personalised mix of services, for example, of preventive, curative or rehabilitative care. Those services may or may not be delivered on an organised programme basis. Thus, it may not be possible to separate each of the components of the package distinctly into prevention, cure or rehabilitation consumption when they are not part of a programme with specific expenditure records. ${ }^{3}$

Health care can be consumed in two ways: by collectives or individuals. ${ }^{4}$ As health status is an attribute of individuals, most consumption of health services is undertaken by specific individuals; and thus is related to private consumption and individual needs. This is important because, although expenditure on health is frequently estimated as an aggregate, the link between the distribution of services among those in need and the distribution of the resources involved is a key issue in policy formulation.

By contrast, collective services are aimed at the whole population (or sections of the population) and aim to improve overall health standards or the effectiveness and efficiency of the health system with benefits to all users simultaneously. These services are diverse and not directly related to individual users but linked to interventions on the whole health system or sub-components, such as the monitoring and evaluation of specific disease control programmes, in addition to governance and administrative services.

\section{Uses of the functional approach}

The main uses of a functional classification are:

- A grouping of health care goods and services by purpose; ${ }^{5}$

- A cross-classification of these groups with other relevant health accounting classifications;

- The generation of indicators, such as relative shares of preventive/curative expenditure, the ratio of inpatient to outpatient spending, and other indicators from cross-classifying with financial or provision information, such as: private spending on groups of health care goods and services (e.g. medical goods paid as out-of-pocket spending) or services by mode of provision (e.g. inpatient/outpatient). Note that indicators needed for national monitoring may differ, and may be linked to more detailed reporting levels.

\section{Features of SHA 2011 functional classification}

The following refinements have been introduced into the functional classification in SHA 2011.

- Functional nomenclature. An effort has been made to enhance the functional approach both in the labels and definitions of the first-level purpose categories. In that regard, individual consumption categories previously linked to mode of provision categories have been renamed on a more functional basis, although the content remains unchanged [e.g. medical goods (HC.5) and ancillary services (HC.4)].

- Current spending. Capital formation is acquired as a means of production, and is an investment. In order to refocus the measurement to that of final consumption, the expenditure associated with capital formation has been moved to a specific capital account. The re-structuring also includes human resource formation and research and 
development services, which do not fit the final consumption purpose and are thus excluded from this classification. The focus on final consumption improves the operation of the tri-axial approach. ${ }^{6}$

- Prevention. The functional category has been better aligned to the purpose of consumption, i.e. one of the objectives of contacting the health system is to receive preventive care. The boundary criteria (as described in Chapter 4) have been applied to better differentiate health prevention from the health care-related categories (HC.R) of SHA 1.0. Refined definitions should ensure comprehensive, exhaustive and mutually exclusive categories and increase the comparability of HC classes across countries. The "prevention and public health" class of SHA 1.0 has been unclear in its content, because the categories were based on a mix of criteria: "public" referred at the same time to government-financed services, place of delivery (public-owned services) and the beneficiaries involved (population priority groups). Thus, "preventive and public health" has been restructured into a preventive class, which is better distinguished by purpose from the curative components (see Tables 5.1 and 5.2 and the definitions developed in the section below).

- Memorandum items have been created to allow further analysis of policy and resource allocation. Two groups are presented, based on their content:

- Reporting Items identify policy relevant categories that are not identified through a specific HC class even though their content falls within the health care boundary: for example, the total expenditure on pharmaceuticals (including that of inpatient care), or an alternative grouping of health care goods and services that are not separately identifiable in the main HC classification, such as TCAM (see Table 5.3 and definitions developed in the section below).

- Health care-related classes also identify policy relevant areas that are related to health but go beyond the health care boundary. This is the case, for example, for programmes that come under the social part of long-term care (LTC) or areas involving cross-sectoral health promotion (see Table 5.1 and definitions developed in the section below).

- Research and development is not part of the population's health final consumption. It has been excluded from the health care-related classes ${ }^{7}$ and is now a memorandum item of the capital account in SHA 2011.

- Education and training of human resources for health (HRH) is not part of health final consumption by the population. It has been excluded from the health care-related classes and is now a memorandum item of the capital account in SHA 2011. ${ }^{8}$

The revised functional health care classification is displayed in Box 5.1. The first-digit categories identify the purpose of health care, or the various potential needs of a consumer of health care. The list reflects the aggregates used by most countries to develop a comparative spending profile. Memorandum items are included, to be measured when relevant at national level, such as where countries have an interest in tracking continued prevention and public health categories according to SHA 1.0. 


\section{Box 5.1. The classification of health care functions at the first-digit level}

HC.1 Curative care

HC.2 Rehabilitative care

HC.3 Long-term care (health)

HC.4 Ancillary services (non-specified by function)

HC.5 Medical goods (non-specified by function)

HC.6 Preventive care

HC.7 Governance and health system and financing administration

HC.9 Other health care services not elsewhere classified (n.e.c.)

\section{Memorandum items: reporting items}

HC.RI.1 Total pharmaceutical expenditure

HC.RI.2 Traditional complementary alternative medicines

HC.RI.3 Prevention and public health services (according to SHA 1.0)

Memorandum items: health care related

HCR.1 Long-term care (social)

HCR.2 Health promotion with a multi-sectoral approach

\section{Rationale of the functional classification}

\section{Categories of health care consumption by purpose}

The first-level categories of the functional classification aim to distribute health consumption according to the type of need of the consumer (e.g. cure, care, prevention, etc.).

The contact ${ }^{9}$ with the system of an individual in search of health care includes a standard set of components that can be disaggregated into a sequence designed to:

- Establish a diagnosis;

- Formulate a prescription and therapeutic plan;

- Complement the process with imaging, laboratory and functional tests for diagnosis and assessment of the clinical evolution;

- Complement the therapeutic plan to include pharmaceuticals and other medical goods as well as procedures such as surgery;

- Monitor and assess the clinical evolution.

This sequence is adjusted to the appropriate type of care based on individual needs; for example, in the case of prevention this can entail monitoring a healthy condition, prescribing a healthy life style, establishing early case detection through imaging, laboratory and functional tests, and in some cases, through the prescription of medical goods, e.g. bed nets as part of a malaria programme or anti-malaria medicines to reduce the risks of acquiring the disease.

A contact with the health system is an event covering one or more of the components described above according to the specific needs for which the sequence is initiated. The approach in this framework is that the basis of measurement is each contact with the health system, and not the entire duration of the disease or health condition. For example, 
during a pregnancy, each visit to the medical officer, laboratory service or antenatal class or each associated provision of medicines is independently accounted for as a contact. A contact is distinct from the complete treatment, which comprises all the contacts to treat a health condition.

The natural history of disease qualifies the various components of the health system contact and allows a breakdown by specific type of service. It displays a rationale for the progression of a disease or other health condition (disorder, injury, ageing), from the moment of exposure, incident or onset, to the factors that cause health conditions (causal agents) until recovery, functional decline or death, and it determines the purpose of each contact with the health system (see Figure 5.1) ${ }^{10}$ Interventions by the health system are intended to handle each of the stages in such a way that the development of the health condition is stopped, and when this is not feasible, it is delayed, or its effects reduced.

The starting point of this process is a healthy condition. At this stage, interventions aim to enhance health status and to maintain a condition of low risk of diseases, disorders or injuries - in other words, to prevent their occurrence (HC.6), through vaccinations or an injury prevention programme, for example. Preventive interventions also cover individuals at specific risk and those who have either no symptoms of the disease or early signs and symptoms, where early case detection will assist in reducing the potential damage by enabling a more successful intervention. Take the examples of breast and prostate cancer, where age and sex affect the risk; certain lifestyle choices increase the risks, as smoking does for lung cancer.

From the onset, a disease, injury or disorder is identified by the emergence of symptoms or signs that lead to a search for an appropriate treatment for or by the patient. When the symptoms correspond to an acute condition, a remission or cure (HC.1) is sought and expected. Many conditions cannot, however, be completely cured and lead to chronic conditions with some degree of functional decline. Treatment then involves recurring contacts for control as well as the patient's personal involvement in monitoring and controlling symptoms and treatment. ${ }^{11}$ Curative care is the most frequent reason why people initially contact the health system. However, based on the specific needs of each consumer the services received typically include a basket of components that mixes preventive and rehabilitative as well as curative care.

Co-morbidity may also occur. When an additional morbid process emerges while the first one is still active, this usually entails additional treatment for the new acute condition. It is also possible that the treatment given during a contact may carry iatrogenic risks, that is, a disease, injury or side effects may be generated by the treatment received, which also require treatment. Complications frequently imply a more complex treatment. A relapse or recurrence is another potential outcome, in which case the treatment has to be re-established or modified. Sequelae, the negative consequences of a condition, can persist.

Impairments, limitations in functioning capacity and consequences of treatment may be rehabilitated (HC.2). Both an acute and a chronic condition may deteriorate, causing disability of some degree of severity, from mild to complete. A decline across several domains of functioning could leave the individual unable to handle their own care, and when rehabilitation is not feasible, a long-term care (HC.3) option is pursued. This aims to maintain the best quality of life and to reduce suffering and limit deterioration. Palliative care is a component of this final stage. 
Figure 5.1. The natural history of disease and the purpose of health care goods and services

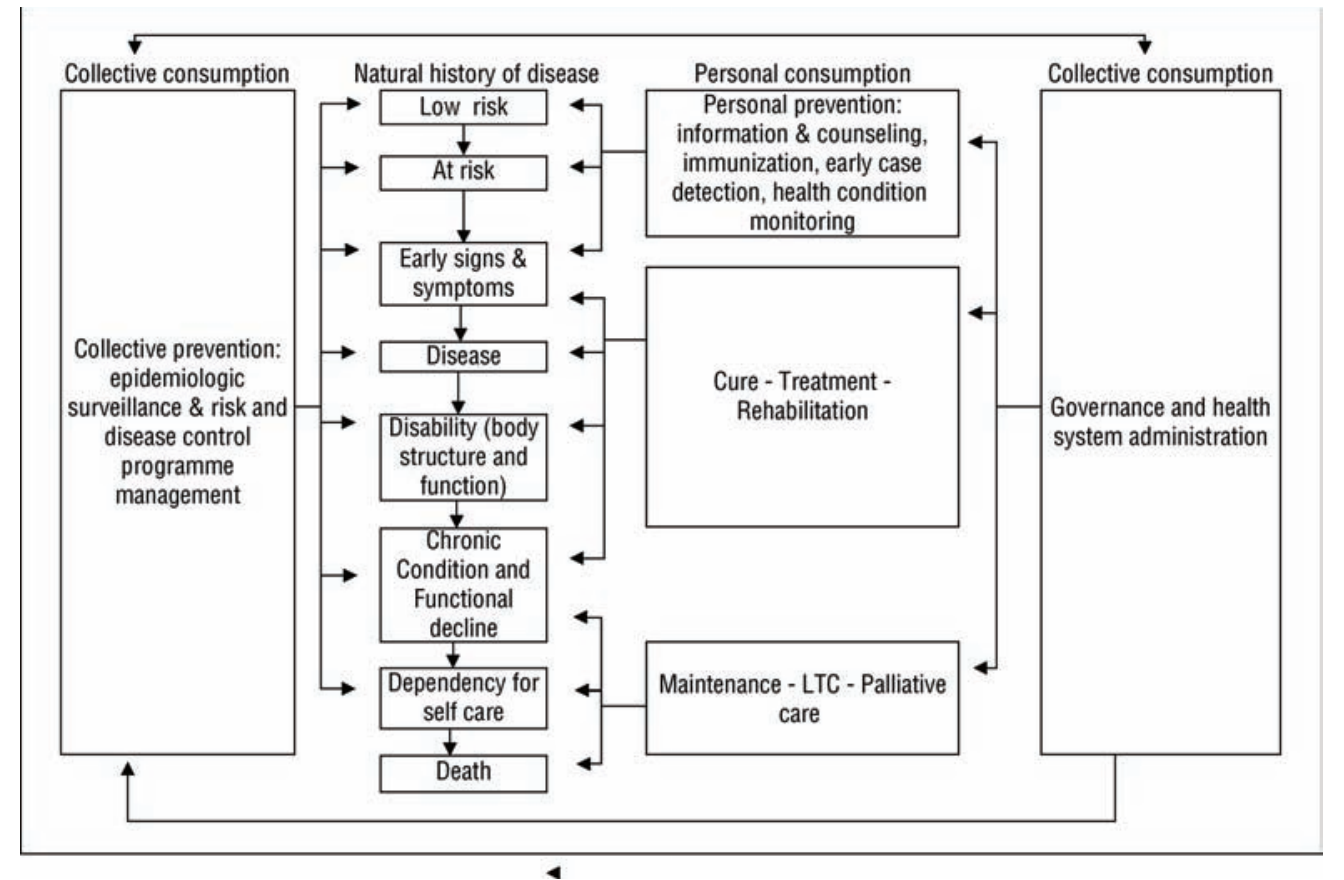

Source: Adapted from Norman (2003).

Collective services are aimed at the whole population (or sections of the population) and aim to improve overall health standards or the effectiveness and efficiency of the health system, which benefits all users simultaneously. This refers in particular to some preventive services (part of HC.6) and to governance and health system and financing administration (HC.7).

An illustration of the application of the structure of the natural history of disease is presented in Figure 5.2, which uses a decision tree to classify transactions based on the purpose of health care. Note that the codes sequence of the HC classification does not follow the pathway of the history of the disease. The codes follow those developed in SHA 1.0 to facilitate continuity in time series.

\section{Mode-of-provision categories}

The categories relating to cure, rehabilitation and long-term care (HC.1-HC.3) ${ }^{12}$ are broken down at the second level of classification by a mode-of-provision (MoP) approach, which is based on the specific organisational and technological arrangements of the services consumed. There is no unique block of goods and services to be consumed under each MoP. Each can correspond to a single product or a group of health care goods and services used to cope with an individual's health condition. The services consumed by type of MoP also vary according to the characteristics of the health care system and to the preferences of both the consumer and those prescribing treatment. ${ }^{13}$

The MoP approach responds to particular policy interests but also recognises the structure of national data sources. It is also meant to differentiate between products that are similar but frequently display a different quality, most notably in terms of the technology utilised and the intensity, length and continuity of the health care interaction. 
Figure 5.2. Decision tree for the functional classification

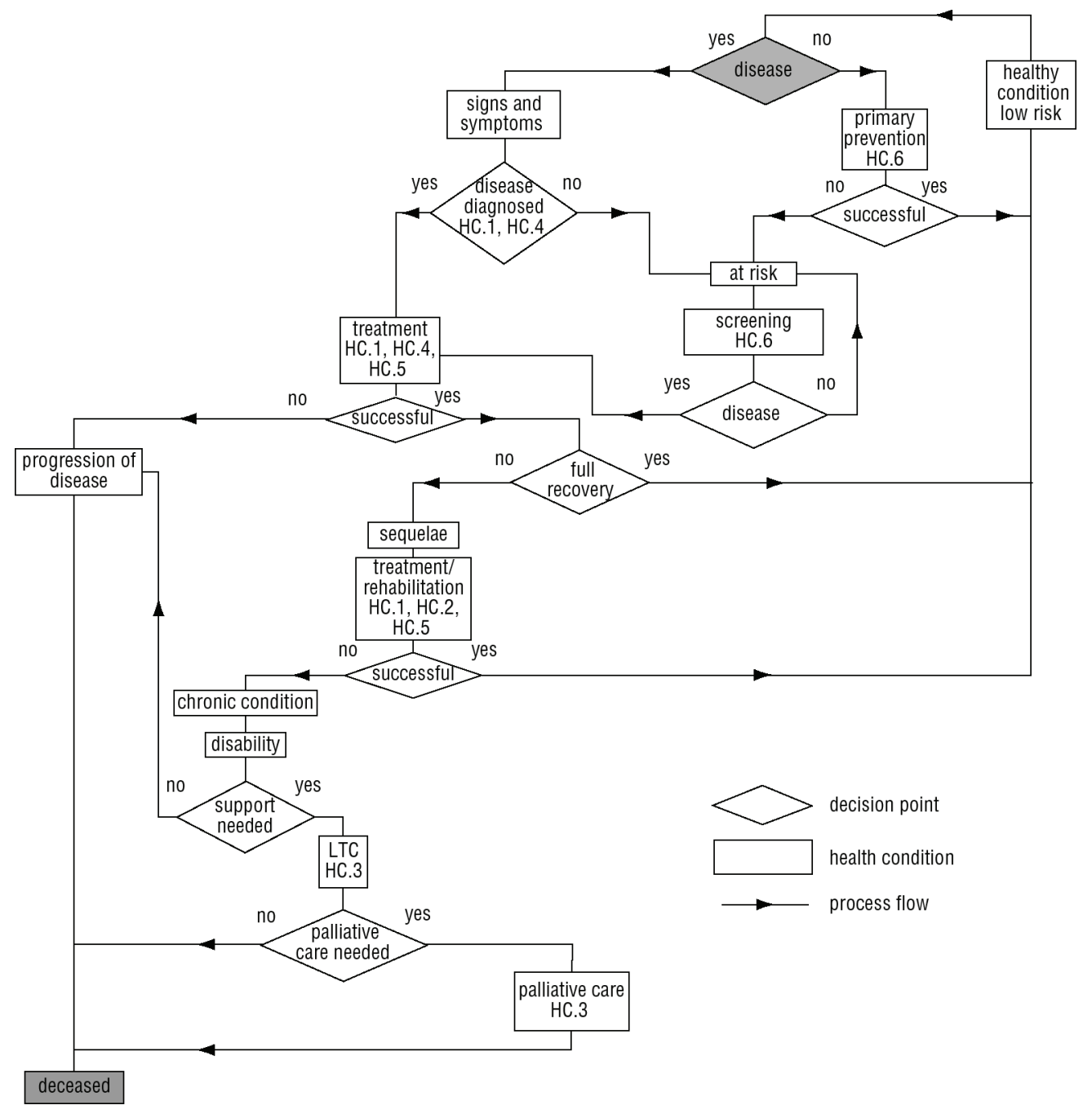

Source: IHAT for SHA 2011.

For example, surgical and some medical non-surgical procedures in inpatient and outpatient settings may be identical in all but one respect: inpatient settings include accommodation and additional nursing care. The role of ancillary services and medical goods are the same regardless of whether they are provided to an inpatient or an outpatient. In all cases, consumption includes the total value of the resources involved in the provision of the service, including management and administrative costs.

The identified MoP categories are: inpatient, day care, outpatient and home-based care. The main criteria to differentiate the categories are:

- Inpatient care and day care involve formal admission to a health care facility, whereas outpatient and home-based care do not;

- Inpatient care involves an overnight stay after admission, whereas day care requires the patient to be discharged on the same day;

- Outpatient and home-based care can be differentiated based on the location from where the services are provided; home-based care is provided at the patient's place of residence, whereas outpatient services are delivered from the health care providers' premises. 


\section{Inpatient care}

An inpatient contact comprises a formal admission into a health care facility for treatment and/or care that is expected to constitute an overnight stay. The classification as inpatient care is irrespective of the type of provider; this may be a hospital, nursing care facility, or facilities classified as ambulatory care providers but which perform occasional procedures requiring inpatient care and are thus able to provide overnight accommodation. It can also include health facilities within any type of establishment that accommodates patients justifying an overnight stay. Tuberculosis hospitals and sanatoriums are often organised to include accommodation along with medical treatment, which is the predominant purpose during a stay in such facilities.

The inclusion of accommodation with medical and ancillary care constitutes the main distinction between outpatient and inpatient care. Accommodation is mostly required because inpatient contacts are typically more complex medical cases that require longer diagnostic procedures and pre- or post-operative intensive surveillance; care with accommodation typically translates into relatively more severe medical cases.

- Contacts lasting less than 24 hours but including an overnight stay, such that the individual leaves the health care facility the day following the day of admission, are normally counted as inpatient care irrespective of the original intention. Emergency cases and urgent admissions should be included only when they result in an overnight stay and formal admission to an inpatient facility, but otherwise are considered as outpatient cases.

- Contacts on a recurrent basis lasting less than 24 hours are classified as day cases, though in some cases these may be night cases, for example, mental health patients who need surveillance during the night (in addition to care provided in day-care centres or at home).

All health care goods and services received during an inpatient contact for care should be included regardless of the provider or the payer, such as when pharmaceuticals are provided directly by health professionals or by relatives who had to acquire them in a pharmacy, either hospital-based or elsewhere.

In the case of developing countries, where services provided by patients' relatives in hospitals are more common, any direct expenditure or reimbursement - including expenditure on food, nursing care and medical goods (if not provided by the health facility) should be recorded under inpatient care. These are often reported in the reimbursement records of the financing schemes or captured in household surveys.

\section{Day care}

Inpatient and outpatient services are practically universal. However, the day-care approach is still incipient in many countries and is often linked to specific objectives such as cost containment and waiting list reduction. In contrast to inpatient and outpatient care, day care comprises planned medical and paramedical services delivered to patients who have been formally admitted for diagnosis, treatment or other types of health care but with the intention to discharge the patient on the same day. Day care can relate to preventive, curative, rehabilitative and long-term care services. Day-care services can be delivered in hospitals, ambulatory premises or free-standing day-care centres. Day-care elective surgery is often performed in institutions or wards that specialise in planned services. This can include any elective invasive therapies provided, usually under general 
or local anaesthesia, to day-care patients whose post-surveillance and convalescence care requires no overnight stay as an inpatient (for example, laser surgery, dialysis and so on). It may also include non-invasive recurrent and planned therapy (such as rehabilitation in individual or group sessions).

In some countries day-care services are, for reporting purposes, often aggregated with outpatient or inpatient services. A contact for a patient who is admitted as a day-care patient, but then due to a complication is retained, should be re-classified as an inpatient case, where feasible. A day patient (or "same-day patient") is usually admitted and then discharged after staying between 3 and 8 hours on the same day. Services for non-admitted patients that are extended to formal admission for day-care are considered as day care. Chapter 14 offers some suggestions on how to deal with aggregated records.

\section{Outpatient care}

Outpatient care comprises medical and ancillary services delivered to a patient who is not formally admitted to a facility and does not stay overnight. An outpatient is thus a person who goes to a health care facility for a consultation or treatment, and who leaves the facility within hours of the start of the consultation without being "admitted" to the facility as a patient. "Outpatient" under the SHA framework has a wider meaning than in many national reporting systems, because it refers to any care offered to a non-admitted patient regardless of where it occurs: the outpatient service may be delivered in the outpatient ward of a hospital (including accident and emergency departments), a dedicated hospital outpatient centre, an ambulatory care centre, a physician's private office, or a health care practice within a work place, school or prison, or even on the street (e.g. vaccinations, injections, blood pressure or temperature measurement), but not at the patient's place of residence.

Health services have evolved to include a set of miscellaneous non-admission services that can be classified as outpatient care, such as consultation and group support services. These are not to be classified as collective, but as individual outpatient care, since such services are delivered simultaneously but to selected individuals without an overnight stay. As an MoP, outpatient care involves a service demand by the patient in a medical setting, regardless of the complexity, location and the type of outpatient facility. As the key criterion concerns the location of the provider rather than the patient, non-face-to-face contacts, such as via e-mail or telephone, generated from the health professional's location are considered as outpatient care, and not home-based care.

- Includes: all clinic visits referred visits, observation services and emergency department visits.

- Excludes: direct purchase of pharmaceuticals, medical goods and ancillary services; and services consumed at home or in a day-care facility.

- Clarifying cases: any outpatient contact that subsequently turns into an admission to a hospital should be modified and recorded as inpatient care. This includes visits to the emergency department, which are recorded as outpatient visits, but when the person is subsequently admitted to the inpatient areas of the hospital are to be recorded as inpatient. ${ }^{14}$ Services provided in the street are also considered as outpatient; however, if a person is stabilised in the street by a paramedical officer and then transported to hospital by ambulance, this whole expenditure would be counted as "patient transport 
and emergency rescue" (HC.4.3). Non-face-to-face encounters, such as telephone, radio or Internet consultations, could be considered as home-based care; however, the criterion is the place from where the service is provided, i.e. the health facility, and therefore should be classed as outpatient care. ${ }^{15}$

\section{Home-based care}

Home-based care comprises medical, ancillary and nursing services that are consumed by patients at their home and involve the provider's physical presence. Included are obstetric services at home, home dialysis and all health care services consumed in a home-setting, regardless of the provider, which may be a relative, a health professional or a community trained worker. This is recorded as home-based care, regardless of the duration of the service. It includes health services consumed at the family home and in other individual or collective residences (apart from nursing homes) where the individual is located on a permanent basis.

Note that the consumption of health services in any health facility (regardless of its size) located within a residence, such as a medical centre in a residence for the elderly or disabled, or in a school or prison, should be classified as inpatient or outpatient according to the aforementioned criteria: that is, if it involves an admission with an overnight stay then it would be referred to as an inpatient service, and if not, then as an outpatient visit.

\section{Further detailed functional groupings}

Each country can opt for a level of aggregation in the reporting as required for its policy analysis and depending on the feasibility related to data and resource constraints. Greater detail within a class does not necessarily imply more detailed reporting, but rather greater clarity about the content of the aggregates. As with other classifications, the greater the detail presented, the less uncertainty there is while classifying, and the more comparable the results. Additional benefits can be found when breakdowns of the HC classes are compatible with those in other available classifications. The division into general and specialised health services for inpatient and outpatient care should be compatible as far as possible with the COFOG (UN, 1999). Within these settings, general and specialised services relate to the technological characteristics of the provider. Specialised services may involve providers that focus on a specific type of patient or need, such as a mental facility service, either for inpatients or outpatients, or a hospital for gynaecology and obstetrics, which may involve more complex technology than a simple maternity unit.

Curative care categories include a breakdown into general and specialised services. A further separation by basic and more complex types of treatment may be a useful input in assessing effectiveness and efficiency, by cross-classifying providers and functions. For countries where this is relevant, some comments are provided in Chapter 15. In the case of outpatient care, an additional category of dental care is added, due to its specific importance. Dental services that are provided in a hospital or through the day-care MoP usually do not represent a large component, and thus are included under specialised services. No third-digit breakdown is proposed for rehabilitative services or long-term care (health) services. 


\section{Health care goods and services non-specified by function}

Health care can be complemented by other goods and services, such as diagnostic laboratory and imaging services, or pharmaceuticals. Such services can be related to preventive care, curative care, rehabilitation or long-term care, thus the purpose of the service itself is unknown. In inpatient care (and day care) such goods and services are normally an integral part of the service package. However, they can be directly consumed as a result of a prescription or individual initiative or self care. ${ }^{16}$ In this latter case, there is often no record linking the treatment to other parts of the health care system, only a transaction linked to a retail sale.

Two categories group this direct consumption: ancillary services ${ }^{17}$ (HC.4) and medical goods (HC.5). For "ancillary services", there is a second-level breakdown into laboratory services, imaging services, and patient transportation and emergency rescue. "Medical goods" are split into pharmaceuticals and other medical non-durable goods, and therapeutic appliances and other medical durables. Pharmaceuticals are then sub-divided into prescribed and over-the-counter (OTC), with a separate subclass for other nondurable goods, while therapeutic appliances are separated into four main goods categories.

\section{Memorandum items}

Different approaches can be taken in accounting for goods and services with a health purpose. The HC classification is based on the natural history of disease and on mode of provision (MoP) approaches. But other approaches (e.g. the type of care: modern or traditional; or the type of component: physical examination, procedures performed, laboratory analysis) may also be relevant for decision-making. In addition, important components of the programme and intervention may go beyond the health care boundary and involve non-health activities (e.g. rehabilitation and long-term care involve health and social services). Therefore, components of health expenditure identified using different approaches and the reporting of components that lie beyond the health care boundary are targeted through two different memorandum categories. These are termed reporting items and health care-related classes, respectively.

\section{Reporting items}

The categories of the functional classification reflect what is considered the most important from a health policy point of view, and in compliance with the rules of any classification construction process, the classes are designed to be both exhaustive and mutually exclusive. However, some components contained within the health care boundary but not fully disaggregated as separate categories on their own may also have strong analytical relevance. This is the case for pharmaceutical consumption, a key component of health care, for which only the direct purchase by the consumer is reported as a separate class: HC.5.1. A total expenditure figure on pharmaceutical consumption is also considered useful to inform decision makers, thus a separate reporting item comprising all pharmaceutical consumption is proposed. Another selected component is Traditional, Complementary and Alternative Medicines (TCAM). TCAM is part of the health system and difficult to isolate, but it is also recognised to be an expanding component. Decisions about health regulations for expanded coverage programmes, as well as a monitoring process by type of delivery, require TCAM information. 
Table 5.1. Classification of health care functions

\begin{tabular}{|c|c|c|}
\hline Code & Description & SHA 1.0 codes \\
\hline HC.1 & Curative care & HC.1 \\
\hline HC.1.1 & Inpatient curative care & HC.1.1 \\
\hline HC.1.1.1 & General inpatient curative care & \\
\hline HC.1.1.2 & Specialised inpatient curative care & \\
\hline HC.1.2 & Day curative care & HC.1.2 \\
\hline HC.1.2.1 & General day curative care & \\
\hline HC.1.2.2 & Specialised day curative care & \\
\hline HC.1.3 & Outpatient curative care & HC.1.3 \\
\hline HC.1.3.1 & General outpatient curative care & HC.1.3.1 \\
\hline HC.1.3.2 & Dental outpatient curative care & HC.1.3.2 \\
\hline HC.1.3.3 & Specialised outpatient curative care & HC 1.3.3 \\
\hline HC.1.4 & Home-based curative care & HC.1.4 \\
\hline HC.2 & Rehabilitative care & HC. 2 \\
\hline HC.2.1 & Inpatient rehabilitative care & HC2.1 \\
\hline HC.2.2 & Day rehabilitative care & HC2.2 \\
\hline HC.2.3 & Outpatient rehabilitative care & HC2.3 \\
\hline HC.2.4 & Home-based rehabilitative care & HC2.4 \\
\hline HC.3 & Long-term care (health) & HC.3 \\
\hline HC.3.1 & Inpatient long-term care (health) & HC.3.1 \\
\hline HC.3.2 & Day long-term care (health) & HC.3.2 \\
\hline HC.3.3 & Outpatient long-term care (health) & part of HC.3 \\
\hline HC.3.4 & Home-based long-term care (health) & HC.3.3 \\
\hline HC.4 & Ancillary services (non-specified by function) & HC.4 \\
\hline HC. 4.1 & Laboratory services & HC.4.1 \\
\hline HC.4.2 & Imaging services & HC.4.2 \\
\hline HC.4.3 & Patient transportation & HC.4.3 \\
\hline HC. 5 & Medical goods (non-specified by function) & HC.5 \\
\hline HC.5.1 & Pharmaceuticals and other medical non-durable goods & HC.5.1 \\
\hline HC 5.1.1 & Prescribed medicines & HC.5.1.1 \\
\hline HC 5.1.2 & Over-the-counter medicines & HC.5.1.2 \\
\hline HC 5.1.3 & Other medical non-durable goods & HC.5.1.3 \\
\hline HC.5.2 & Therapeutic appliances and other medical goods & HC.5.2 \\
\hline HC.5.2.1 & Glasses and other vision products & HC.5.2.1 \\
\hline HC.5.2.2 & Hearing aids & HC.5.2.3 \\
\hline HC.5.2.3 & $\begin{array}{l}\text { Other orthopaedic appliances and prosthetics (excluding glasses and } \\
\text { hearing aids) }\end{array}$ & HC.5.2.2 \\
\hline HC.5.2.9 & All other medical durables, including medical technical devices & HC.5.2.4- HC.5.2.9 \\
\hline HC. 6 & Preventive care & $\begin{array}{l}\text { HC.6, part of HC.R.4, } \\
\text { HC.R.5 }\end{array}$ \\
\hline HC.6.1 & Information, education and counseling programmes & $\begin{array}{l}\text { Part of HC.6.9, part of HCR } \\
\text { 4, HC.R.5 }\end{array}$ \\
\hline HC.6.2 & Immunisation programmes & Part of HC.6.3 \\
\hline HC.6.3 & Early disease detection programmes & Part of HC.6.3, HC.6.4 \\
\hline HC.6.4 & Healthy condition monitoring programmes & $\begin{array}{l}\text { Part of HC.6.1, HC.6.2, } \\
\text { HC.6.5 }\end{array}$ \\
\hline HC.6.5 & Epidemiological surveillance and risk and disease control programmes & HC.6, part of HC. $4, \mathrm{HC} .5$ \\
\hline HC.6.6 & Preparing for disaster and emergency response programmes & Part of HC.6 \\
\hline HC.7 & Governance, and health system and financing administration & HC.7 \\
\hline HC.7.1 & Governance and Health system administration & HC.7.1 \\
\hline HC.7.2 & Administration of health financing & HC.7.2 \\
\hline HC.9 & Other health care services not elsewhere classified (n.e.c.) & \\
\hline \multicolumn{3}{|c|}{ Memorandum items } \\
\hline \multicolumn{3}{|c|}{ Reporting items } \\
\hline \multirow[t]{2}{*}{ HC.RI.1 } & Total pharmaceutical expenditure (TPE) & \\
\hline & of which Inpatient pharmaceutical consumption & \\
\hline
\end{tabular}


Table 5.1. Classification of health care functions (cont.)

\begin{tabular}{cll}
\hline Code & Description & SHA 1.0 codes \\
\hline HC.RI.2 & Traditional, Complementary and Alternative Medicines (TCAM) & HC.1-HC.6.1 \\
HC.RI.2.1 & Inpatient TCAM & HC.1.1 \\
HC.RI.2.2 & Outpatient and home-based TCAM & \\
HC.RI.2.3 & TCAM goods & \\
HC.RI.3 & Prevention and public health services (according to SHA 1.0) & HC.6 \\
HC.RI.3.1 & Maternal and child health; family planning and counseling & HC.6.1 \\
HC.RI.3.2 & School health services & HC.6.2 \\
HC.RI.3.3 & Prevention of communicable diseases & HC.6.3 \\
HC.RI.3.4 & Prevention of non-communicable diseases & HC.6.4 \\
HC.RI.3.5 & Occupational health care & HC.6.5 \\
HC.RI.3.9 & All other miscellaneous preventive care services & HC.6.9 \\
Health care related & & \\
HCR.1 & Long-term care (social) & \\
HCR.1.1 & In-kind long-term social care & Part of HCR.6 \\
HCR.1.2 & Long-term social care cash-benefits & Part of HC.R.7 \\
HCR.2 & Health promotion with multi-sectoral approach & HC.6, HC.R.4, HC.R.5 \\
\hline
\end{tabular}

Source: IHAT for SHA 2011.

\section{Health care-related classes}

The functional classification focuses on the grouping of health care goods and services consumed with a defined health purpose. A similar set of services and goods can be consumed with a non-health purpose. This is the case where health care is inter-linked with well-being or with social care, such as medical services with a cosmetic non-health purpose or social support as part of long-term care. Some of this related spending may also be of major relevance for policy purposes. This is the case for the expenditure on social services and cash benefits that are offered as part of long-term care expenditure and HIV/AIDS control and support programmes, for which a total value, including both the health care component as well as the social care component, is vital for the purpose of resource allocation. The classification therefore proposes some additional health care-related classes that allow the construction of relevant indicators to sum up the health and nonhealth components.

Additional classes could be included for country-specific policy requirements. One case could be the registration of purely cosmetic health activities, as these are provided by qualified health professionals in a professional environment using specific health knowledge and techniques, but do not meet the criterion of a primary health intent. However, in some countries the provision and consumption of cosmetic health services is big business.

Detailed descriptions and definitions of both the reporting items and health carerelated classes are included in the explanatory notes at the end of this chapter.

\section{Explanatory notes to the ICHA-HC classification of health care functions}

\section{HC. 1 Curative care $^{18}$}

Curative care comprises health care contacts during which the principal intent is to relieve symptoms of illness or injury, to reduce the severity of an illness or injury, or to protect against exacerbation and/or complication of an illness and/or injury that could threaten life or normal function. 
A contact for curative care comprises an individual contact with the health system and can be made up of a sequence of components, such as to establish a diagnosis, to formulate a prescription and therapeutic plan, to monitor and assess the clinical evolution or to complement the process by imaging, laboratory and functional tests for diagnosis and evolution assessment. The contact can also include various therapeutic means such as pharmaceuticals and other medical goods (e.g. ortheses, such as glasses, and prosthetic appliances, such as artificial teeth or limbs), as well as therapeutic procedures, such as surgical procedures, which require additional follow-up. Routine administrative procedures such as completing and updating patient records are also an integral part of the service.

- Includes: all components of the curative care of illness or the treatment of injury; the surgery performed; diagnostic and therapeutic procedures; and obstetric services.

- Clarifying cases: treatment and disease management contacts for chronic diseases for which a cure is not feasible should be recorded as curative care when a partial recovery is expected, regardless of the initial clinical condition of the patient (including dependent patients). When a decline in health condition is expected in dependent cases, coupled with increasing dependency needs, this should be classified as long-term care (health): HC.3.

\section{Curative care by mode of provision}

The second level refers to the categories of inpatient, day care, outpatient and homebased curative care (see description of modes of provision above). In all cases the main purpose of curative care remains the same, but the technology and place of provision change: in the case of an overnight stay in a health care facility the mode of provision is inpatient, or home-based if services are consumed at the patient's place of residence. When a patient is admitted for planned care or treatment involving specific organisational arrangements but does not involve an overnight stay then this is day care, ${ }^{19}$ otherwise it is an outpatient contact.

- HC.1.1 Inpatient curative care;

- HC.1.2 Day curative care;

- HC.1.3 Outpatient curative care;

- HC.1.4 Home-based curative care.

\section{General and specialised care}

Since curative care categories can cover more than a third of health expenditure, a further breakdown may be appropriate. Curative care can be broken down at a third-digit level into general and specialised care under each mode of provision. The underlying principles are:

a) More common health care needs can be solved through less complex services (basic or general care) while a narrower set of needs require an increasing level of technological complexity (specialised care);

b) The health system usually operates based on the selectivity of needs, with wider availability of basic or general services, generally at lower cost and with diverse means of use (in dense or scattered population areas). A progressive reduction in service availability is expected for more complex health care needs, with treatment requiring 
higher technology. They are also likely to be of higher cost and often accessed through a referrals system;

c) There can be a gap between health needs and the availability of services and resources required, e.g. some countries lack high technology equipment to deal with cancer or renal failure cases, thus only basic care is consumed regardless of care needs;

d) The disaggregation is relative to the technology and resources available in the whole country. Levels of technology can differ in various countries, but specialised care should always refer to a higher level of complexity than services classified as basic or general.

General care. General care is often the entry point to the health care system, before referral is made to a specialist when a more complex health condition is found. General care involves the components of the contact for care, such as routine examinations, medical assessments, prescription of pharmaceuticals, routine counselling of patients, dietary regime, injections and vaccination (unless covered under preventive programmes) of all patients. It includes, for instance, basic maternity and routine diagnosis and followup of reproductive health for non-complicated cases and can be part of an initial medical consultation or check-up, or part of a follow-up inpatient or outpatient contact.

In reality, an initial contact can be made with a specialised health provider as the entry point. These initial contact services, including basic diagnosis and assessment, are of a general type. Ideally, records should be appropriate to classify these basic services as such, regardless of the specialised level of the provider. General care excludes curative care services with a higher level of specialisation.

Specialised services. These services relate to curative care involving a higher level of technology, which are expected to be consumed by selected cases of less frequent and more complex health care needs. These services are linked to a deep but narrower set of conditions that require a high technology service, involving more complex diagnostic and treatment procedures. They are frequently performed by providers devoted to a particular condition, disease or class of patients. There are four basic medical fields, which are internal medicine, gynaecology and obstetrics, surgery and paediatrics. Specialised services often involve a breakdown of these fields, such as neurosurgery (surgery), allergology (internal medicine), paediatric allergology (paediatrics) or reproductive medicine or genetics (gynaecology and obstetrics), etc.

General inpatient care (HC.1.1.1) covers four types of services: general surgery, general internal medicine, general paediatrics and general gynaecology and obstetrics. Admissions focus on routine treatment, such as maternity cases without complications, appendicitis, hernias, diarrhoea and dehydration in children, non-complicated diabetes and so on.

General outpatient services (HC.1.3.1) also are expected to cover the more frequent and uncomplicated cases of all medical fields, such as monitoring and non-complicated cases of communicable and non-communicable common paediatric diseases and noncomplicated cases of acute and chronic disease follow-up in adults.

With respect to dental care, curative care services focus on oral health, including teeth, gum and other related disorders. It includes the whole range of services usually performed in an outpatient setting, such as tooth extraction, the fitting of dental prostheses, and dental implants and orthodontics. The vast majority of dental care is performed as outpatient care, and therefore a separate third-digit category for dental care 
is included under the outpatient mode of provision (HC.1.3.2). Dental surgery provided as an inpatient service is classified as an inpatient specialised service (HC.1.1.2).

A further breakdown at the fourth-digit level by type of speciality or by component, such as for performance of procedures, pharmaceuticals and consumption of ancillary services included in a curative inpatient service, could also be used.

\section{HC 2 Rehabilitative care}

Rehabilitation is an integrative strategy that aims at empowering persons with health conditions who are experiencing or are likely to experience disability so that they can achieve and maintain optimal functioning, a decent quality of life and inclusion in the community and society.

Whereas curative services focus primarily on the health condition, rehabilitation services focus on the functioning associated with the health condition. Rehabilitation services stabilise, improve or restore impaired body functions and structures, compensate for the absence or loss of body functions and structures, improve activities and participation, and prevent impairments, medical complications and risks. Functioning and disability are conceived as a continuum that embraces everyone at some time during the life course. ${ }^{20}$ Functioning involves a dynamic interaction between health conditions, environmental factors and personal factors. Rehabilitation is relevant over the course of the health condition, along a continuum of care from the hospital to rehabilitation facilities and to the community and across sectors from health, education and labour to social affairs. As stated in Chapter 4, the criteria boundary is also applicable to rehabilitative care; thus, only rehabilitative components with a primary purpose related to health functioning should be included. For comparative purposes, labour and social purposes have to be identified and excluded from health care.

Rehabilitation services are consumed by individuals experiencing functional difficulties associated with a broad range of health conditions (disease, disorder and injury), which may be acute or chronic, congenital or acquired, and affect people with disabilities ${ }^{21}$ of all ages, independent of, or in conjunction with, specialist health care services (e.g. hip replacement, heart transplant, specialist eye treatment or treatment for acute depression). Rehabilitation services are based (where possible) on a functional assessment and diagnosis to determine the goals and plan for rehabilitation. These are followed by agreed interventions (including biomedical and technological approaches as well as peer support) to optimise a person's capacity. Rehabilitation plans are monitored and adapted in accordance with an individual's needs and resources. The careful monitoring of outcomes related to specific interventions may help determine improvements to the intervention so as to optimise functioning and minimise disability.

The scope of rehabilitation is wide and includes psychological, assistive technological, environmental, cardiopulmonary, geriatric, neurological, orthopaedic and paediatric rehabilitation, among others. As rehabilitation involves all areas of an individual's functioning, it may happen that for some of them the health care boundary criteria are not matched, notably in areas that are job-related, social-related or leisure-related, when the primary focus goes beyond the health purpose (see Box 5.2). For comparative purposes, a selection of those primary health purpose components should be made.

- Includes: consumption of services aimed at reaching, restoring and/or maintaining optimal physical (e.g. complementing body structure through a prosthesis), sensory (e.g. complementing 
hearing recovery with a prosthesis), intellectual (e.g. recovering memory capability after a stroke), psychological (e.g. reducing depression and stress through supported learning to use a prosthesis) and social functional levels (e.g. by re-establishing control of basic functions such as swallowing and speaking after a stroke), all of which are health consequences of disease, disorders or injury.

- Excludes: rehabilitative services with a primary social, leisure or labour purpose. Some examples of the social focus are those linked to a primary purpose of creative, cultural and educational interactive routines, as well as vocational training and re-training and education and job placement.

- Clarifying cases: there can be an overlap of curative treatment, e.g. in the case of stroke, when complemented with early rehabilitation treatment, such as speech therapy and physiotherapy. Both functions can be run in parallel. This may also be a possible overlap between rehabilitation services and long-term care services: rehabilitation is consumed on a continued or recurrent basis with a recovery purpose, whereas long-term care has a maintenance purpose.

\section{Rehabilitation by mode of provision}

Rehabilitation services can be divided into the same four modes of provision: inpatient, day care, outpatient and home-based. The four modes of provision could be further broken down into the various specialised rehabilitation types identified as appropriate to the health care boundary:

- HC.2.1 Inpatient rehabilitative care;

- HC.2.2 Day rehabilitative care;

- HC.2.3 Outpatient rehabilitative care;

- HC.2.4 Home-based rehabilitative care.

It should be noted that while preventive, curative and rehabilitative care services are very different in their purposes and characteristics, in terms of health statistical systems (e.g. hospital records) it may be difficult to separate into the three components. In such cases, a single aggregate of curative-rehabilitative care has been used for data collection and reporting purposes. Alternative record development or prorata procedures can also be used, which should be clearly indicated in the methodological information.

\section{HC.3 Long-term care (health)}

Long-term care (health) consists of a range of medical and personal care services that are consumed with the primary goal of alleviating pain and suffering and reducing or managing the deterioration in health status in patients with a degree of long-term dependency. ${ }^{22}$

To date, estimates of spending on services for long-term health care have been mostly limited to higher-income countries, due to the fact that in most low- and middleincome countries (LMIC) long-term health care is provided as informal care, i.e. usually consumed at home, provided by relatives and without any transaction or record involved. ${ }^{23}$ However, it is evident that needs are emerging and expanding in all countries, ${ }^{24}$ along with the rise in life expectancy, an epidemiological transition and the increasing involvement of health systems with long-term care in the wake of social and economic changes. 


\section{Box 5.2. Examples of rehabilitation services}

Occupational therapy services enhance an individual's skills, capacity and performance in interaction with their personal and environmental contexts. Services may be directed at the individual or the environment to improve activities (e.g. activities of daily living) and participation (e.g. speaking recovery capabilities). Occupational therapy is centred on the individual, but may also involve the family, carers and the broader community. Occupational therapy services include, among others:

- Therapeutic use of meaningful and purposeful occupations (occupation understood as any activity on which time is spent by a person),

- Adaptation of environments and processes to enhance functioning and participation,

- Programmes involving graded tasks and activities as prerequisites to engagement in functional training for activities of daily living (including self care),

- Prescription or design, fabrication, application, adaptation and training in the use of assistive technology or orthotic or prosthetic devices.

Physical therapy involves services to "develop and maintain maximum movement potential and functional ability throughout the lifespan" (WCPT, 2007). This includes services to restore the integrity of body systems essential to movement, maximise functional ability and recuperation, minimise incapacity, and enhance the quality of life in individuals and groups of individuals, by dealing with functional limitations and disabilities in relation to the physical, psychological and emotional spheres and in terms of social well-being. Circumstances where movement and function are threatened include congenital, age, injury, disease or determined environmental factors. Services are adapted on an ad-hoc basis and may include, among others:

- Manual therapy techniques, electrotherapeutic, physical agents and mechanical modalities (WCPT, 2007);

- Prescription, application and, as appropriate, fabrication of devices and equipment;

- Skin repair and protection techniques, airway clearance techniques (e.g. in obstructive respiratory diseases) and therapeutic exercise.

Physical and rehabilitation medicine (PRM) involves services to diagnose health conditions, assess functioning and prescribe biomedical and technological interventions that treat health conditions and optimise functional capacity. The services include, among others:

- Prescription of an integrated range of biomedical, psychological and social interventions, e.g. drug treatment, physiotherapy, occupational therapy, speech and language therapy, dysphagia management, rehabilitation nursing, neuropsychological interventions, psychological interventions, nutritional therapy, provision of assistive technology, prosthetics and orthotics and the education of patients and families.

Psychological and behavioural rehabilitation (PBR) is a collection of services to diagnose impairments in cognitive functions and other psychosocial functional limitations that affect the life and well-being of individuals and the manner and effectiveness of dealing with their health conditions and disability. Among PBR services are:

- Individual psychotherapy, including cognitive behavioural therapy and neurocognitive therapy to improve the self-recognition of health conditions related to psychological and behavioural problems and empowerment with skills to manage them to enhance the quality of life; 


\section{Box 5.2. Examples of rehabilitation services (cont.)}

- Psycho-education and adaptive strategies, reduction of expressed emotion, behavioural management, and for primary care-givers, including the family, services to improve supportive social networks.

Prosthetics and orthotics rehabilitation aims to enhance the quality of life for people with physical disabilities who require improvements in mobility or independence, through practices associated with the provision of prosthetic and orthotic care, rehabilitation engineering and related areas such as wheeled mobility (ISPO, 2005). The technological devices to complement the function (orthoses) or substitute the structure (prostheses) of the human body are a key component of these services, which include, among others:

- The formulation of treatment through examination, prescription of devices and related rehabilitation;

- The fabrication and fitting of the device, including instructing the user in the use and care of the device;

- Evaluation and follow-up, including maintenance, repair and replacement of the device.

Speech and language therapy aims at restoring people's capacity to communicate effectively and to swallow safely and efficiently. It aims at identifying types of communication problems and the best way to treat them. As such, the services include, among others:

- Clinical and/or instrumental screening, assessment, identification, diagnosis, treatment and management of disorders related to speech, voice, language, fluency, and swallowing that impact on the individual's ability to communicate.

Selection and development of augmentative and alternative communication systems and devices for individuals who are limited in their ability to communicate verbally, and provision of education and training in their use.

To plan services and develop policy, there is a need for separate reporting of the health and social care components as well as for measures of total long-term care (LTC) ${ }^{25}$ Due to the strong link between long-term care and the ageing process, policy interest in many countries is understandably centred on elderly age groups. Therefore, a differentiation of long-term care by dependency level, with a cross-classification by age, is likely to be of significant policy relevance; for instance, if health promotion for the aged is successful, the need for long-term health care services should be delayed until more advanced ages. It may also be important to break down age-related payment strategies so as to link the various layers to public and private payments as well as to the public-private mix in provision (Huber and Rodrigues, 2008).

From a final use point of view, LTC typically comprises an integrated package of services and assistance to patients with an increased level of dependency (also understood as impairment, activity limitation and/or participation restriction) on a continued or recurrent basis, and over an extended period of time. The greater the dependency level, the more comprehensive the set of services included in the package. A continuum of care can be tracked, from more intensive medical or nursing services, through personal care services, to lower-level social assistance-type services and other social care. This care is aimed at the dependent population with chronic or recurrent psychiatric conditions, such as physically disabled people and mental health and substance abuse patients. 
The continuum of care may not necessarily require the whole range of services offered or the same delivery path. For example, care may consist of regular, short-term health interventions over a long period, or recurrent and chronic consumption over extended periods. In some cases, long-term care implies supportive care offered to people at any stage of their condition, or palliative care, in the case of life-threatening illness. It also includes terminal care, understood as the management of patients during the last months of life. Even with incurable diseases, many people may live with a functional impairment for many years, and in some cases lead an otherwise largely normal life. Terminal cancer patients receiving palliative care may have radiotherapy or chemotherapy treatment courses from time to time to keep their condition under control. Palliative care works alongside these "active" treatments to promote comfort and well-being.

Note that when a need emerges for an episode of curative acute care, unrelated to the dependent condition, this should be considered as curative care, and not long-term care. However, in frail patients an acute health episode can often evolve into a chronic condition, and because of dependence, can result in more complex long-term needs.

The various components of long-term care can be distinguished as follows (see Figure 5.3 below):

- Medical or nursing care includes the management of symptoms involving medical, paramedical and nursing care services, such as relieving pain and other symptoms, administering medication, performing medical diagnoses and minor surgery, dressing wounds, health counselling to families, and providing emotional and spiritual support for the patient and their family members. Such care includes a) a range of preventive services, notably to avoid a greater deterioration of the patient's frail health condition, b) a range of chronic disease management situations, c) a fair amount of rehabilitative care, to recover functionality, d) care aimed at retarding or reducing deterioration or maintaining functionality: in short, a high level of quality of life assurance, regardless of the type of health ailment.

- Personal care services are provided in response to limitations in self-care primarily due to disability and illness. These services provide help with activities of daily living (ADL) such as: eating, bathing, washing, dressing, getting in and out of bed, getting to and from the toilet and managing incontinence. Most inpatient care as well as some day-care and home-based services will include personal care services as part of the package of services consumed. These services are typically administered directly or under the supervision of nursing staff. These services are included within the health care boundary because the purpose of this type of care is linked to survival and the maintenance of health status. In addition, the need for personal care services is more often than not linked to some underlying medical condition .

- Assistance services relate to care that enables a person to live independently in a house or apartment. They provide assistance with tasks of household management (i.e. instrumental activities of daily living, IADL), such as shopping, laundry, vacuuming, cooking and performing housework, managing finances, using the telephone, etc. These services are typically provided under home help services, assisted living arrangements, etc.

- Other social care services involve community activities and occupational support given on a continuing or recurrent basis to individuals, such as activities whose primary purpose is social and leisure. 
A consistent functional approach, based on the purpose of the contact for care, would imply that care over a long or indefinite period, with nursing or personal care services as the dominant component, is the basis for inclusion within the health care boundary. On the other hand, a contact with the primary purpose of enabling independent living and interaction with the environment, as in the case of home help or assisted living, should be outside the health boundary [see Long-term care (social) HCR.1]. Figure 5.3 describes the boundary of long-term care.

\section{Figure 5.3. The health and social boundary of long-term care (LTC)}

\begin{tabular}{|l|l|l|l|l|l|}
\hline \multicolumn{2}{|c|}{ Boundary } & \multicolumn{4}{|c|}{ Primary long-term care needs } \\
\cline { 3 - 6 } \multicolumn{2}{|c|}{} & $\begin{array}{c}\text { Medical or } \\
\text { nursing care }\end{array}$ & $\begin{array}{c}\text { Personal care } \\
\text { services } \\
\text { (ADL) }\end{array}$ & $\begin{array}{c}\text { Assistance } \\
\text { care services } \\
\text { (IADL) }\end{array}$ & $\begin{array}{l}\text { Other social } \\
\text { care services }\end{array}$ \\
\hline \multirow{3}{*}{ Limited } & \multirow{3}{*}{ HC.3 } & & & & \\
\cline { 2 - 6 } & & & & & \\
\cline { 2 - 6 } & HC.R.1 & & & & \\
\cline { 2 - 6 } & & & & & \\
\hline
\end{tabular}

Source: IHAT for SHA 2011.

In practice, what is frequently found is that nursing, personal and social care services are provided together in an integrated package of services, particularly for inpatient and day care. For home-based care, different services may be provided together, or provided and accounted for separately.

\section{Long-term care boundaries and measurement issues}

The health function (purpose of care) defines the boundary, irrespective of the provider, which in the case of long-term care can be a health professional, community worker or, in the case of home-based care, a relative. Inclusion should also be independent of the financing scheme to cover the care. However, due to differing administrative, financing and provision standards, the national boundaries of long-term care may not necessarily be aligned with the SHA-defined boundaries. Given the lack of direct records for the purpose, decisions need to be made about how to approach the measurement in a standardised way. Unless records at the individual level are available, which is not feasible in most countries, an alternative source should be progressively developed to ensure the required reporting (see suggestions for apportioning and reporting strategies in Chapter 14). Additional criteria to deal with the functional boundaries of long-term care within health care are:

- Personal care services are most frequently linked to underlying health conditions ${ }^{26}$ and often accorded based on a medical assessment or an input from a medical professional. They are thus reported as health care;

- When, due to a higher dependency level, social assistance and other social care services are integrated into a package of care along with medical and personal care services, then they are also included as health care;

- Social long-term care services in themselves are not considered part of health care; 
- When the consequences of a disease are not associated with dependency, such as hearing disabilities, then they are not included under HC.3, regardless of their length and severity;

- If there is a need for continual care to handle a dependency, e.g. care of persons with a mental or physical disability, then it is included within the health care boundary.

\section{Box 5.3. Assessing long-term care needs}

Typically an assessment of the patient or beneficiary is used in order to determine the level of care and the type of long-term care service package consumed. Within the health system there are two different models for assessing the construct "functioning/disability": the "activities of daily living (ADL)" approach (or Katz/Barthel model), and the "Functioning" (ICF) approach developed by WHO. The ICF was developed to provide a more comprehensive framework, based on the view of a health condition or disease as the interaction of body function and structures, activities and participation, which are in turn impacted on by social and environmental factors. The importance of participation as an outcome is also highlighted (WHO, 2001). Dysfunctions in ADL and IADL are considered to be activity limitations within the ICF framework.

The use of these two approaches has not been complementary in the assessment of functioning, particularly in the ageing sector, where the ADL approach has been more specifically employed. In the past, many documents related to functional dependency produced by European experts on ageing have used the ADL approach, while in most recent legislation and policy documents European countries and agencies have adopted the ICF model. ${ }^{27}$ The use of a classification of dependency or personal functioning is itself a means to assess the need for services, rather than part of the HC classification itself. However, it should be borne in mind that the ICF is an official classification adopted by an increasing number of countries (Salvador-Carulla and Gasca, 2010).

The "length" of care can often invoke a specific mode of financing, i.e. once the care continues beyond a threshold period, for example, six months. In some countries, payments may start on day one but be restricted to certain conditions. Other country's records would allow measurement only based on the primary purpose of the provider- that is, whether the facility is primarily a medical or social facility. In other systems, insurance protection typically covers only part of the LTC, and sometimes carer relatives receive some compensatory transfers, which may include training.

In many cases, particularly middle- and low-income countries, long-term care is provided by relatives at home without any type of compensation, either in-kind or cash transfers. The value of informal carers is, however, outside the SHA boundary due to the absence of a valued transaction.

In a few higher-income countries there is a trend to formalise assistance, notably among the eldest sections of the population. Records and reporting strategies are, however, quite limited on LTC household consumption. Although some programmes support carers' skills and compensate them for their work, these may not be specific to health and may be recorded under social care. 


\section{Long-term care (health) by mode of provision}

Different modes of provision can result from the structure of the health system as well as from the epidemiological profile of the beneficiary. Modes of coping with long-term care needs are also evolving over time. In principle the greater the dependency, the more specialised and intensive are the services that are likely to be consumed.

\section{HC.3.1 Inpatient long-term care (health)}

This item comprises long-term care (health) services provided in a health care facility (hospital, nursing home) and requiring an overnight stay with medical supervision. The package of services covers nursing and/or personal care, usually provided together, along with a range of other components such as accommodation and support services.

- Includes: nursing and personal care typically for moderate or severe dependent needs, such as quadriplegic or end-of-life care, delivered in a range of nursing homes and other specialised long-term care facilities. Inpatient long-term care for mentally disabled and substance abuse patients is included where the care is due to chronic or recurrent psychiatric conditions and a prolonged degree of functional limitations and/or a need for help or surveillance. It includes long-term care services provided to inpatients in longstay hospital wards or other hospital care settings. Accommodation services are considered part of long-term health care provision.

- Excludes: residents of establishments where little or no medical or nursing care is provided on site. Acute care contacts in long-term care patients should be included under HC.1: Curative care.

- Clarifying cases: key to this category is the purpose, e.g. psychiatric hospital services are classified as curative inpatient care when they aim at dealing with acute needs through medical and nursing care; whereas psychiatric long-term care involves dependent patients with little or no recovery expectation who are institutionalised predominantly for nursing care and periodic medical visits.

\section{HC.3.2 Day cases of long-term care (health)}

This item comprises planned long-term care (health) services in a health care facility but without an overnight stay. Services may be provided in a hospital or nursing home or in a dedicated or stand-alone day centre facility.

Often neglected in formal statistical treatment are night cases, which are reported as day cases e.g. elderly patients with a disturbed sleeping pattern but normal behaviour during the day, living with relatives during the day, but admitted into an institution at night. A parallel form concerns mentally unstable persons, who may even pursue a profession during normal business hours, but stay in a psychiatric institution at night. Another case is respite care for LTC patients who live with relatives during much of the year but are "admitted" to a facility during the family's vacation period.

\section{HC.3.3 Outpatient long-term care (health)}

This comprises long-term care (health) services that have the purpose of managing damaged health conditions and the associated clinical difficulties. Dependent patients with a chronic condition may require periodic verification of medication doses and of the evolution of their condition, and advice on how to handle symptoms that emerge as the disease evolves. These services may refer to regular outpatient visits or to the increasing provision of remote monitoring services for LTC patients. 
This category may represent a reporting challenge at present, because health statistics may currently have difficulty distinguishing between different types of outpatient care services and other home-based services. More detailed records would be required to facilitate this reporting. In the absence of such data, estimates based on human resources, utilisation rates or unit cost information may be useful.

\section{HC.3.4 Home-based long-term care (health)}

This comprises long-term care (health) services provided to persons within their own home, or in residential settings such as adapted housing that can be considered as their home, rather than in an "institution". Such residential facilities include community-based settings, such as adapted housing, which provide an individual housing environment in combination with certain services, such as health protection and surveillance, often for elderly people who are becoming more dependent. It can involve specialised health care at home and services to support informal (family or community) care. Note that long-term care services of a lower-level social care nature (such as home help) may be included as part of a package of home-based care. If such services cannot be separately accounted for and are not the dominant component of the package, they should be included under HC.3.4; if, however, they are the dominant feature, the complete package of care services should be included under HCR.1 Long-term care (social).

\section{HC.4 Ancillary services (non-specified by function)}

Ancillary services are frequently an integral part of a package of services whose purpose is related to diagnosis and monitoring. Ancillary services do not, therefore, have a purpose in themselves: the purpose is to be cured, to prevent disease, etc. The ancillary service is aggregated within the first-digit purpose class and the second-digit MoP in which it was consumed. For inpatient, day care and hospital outpatient services, they are not usually identified as separate categories.

Therefore, only a part of the total consumption of ancillary services is made explicit by reporting the consumption of such services in the "non-specified by function" category, such as when the patient consumes the service directly, in particular during an independent contact with the health system.

The independent consumption of ancillary services may be associated with either early case detection as a part of prevention (HC.6), monitoring a treatment or a health condition - cure (HC.1), rehabilitation (HC.2) or long-term care (HC.3). These services are also related to consumption that has no identified mode of provision. For example, laboratory tests or an interpretation of imaging can be purchased as a result of the consumer's own initiative, or a medical test could be used for a second opinion for inpatient or outpatient cases or home-based care.

The content of ancillary services related to diagnosis and monitoring is split at the second-digit level between laboratory services (HC.4.1) and imaging services (HC.4.2). It also includes patient transportation and emergency rescue (HC.4.3).

\section{HC.4.1 Laboratory services}

This item comprises a variety of tests of clinical specimens aimed at obtaining information about the health of a patient. Laboratory tests are an integral part of the consumption of any patient, and constitute a guide for diagnosis and treatment choice. 
Laboratory services (HC.4.1) includes the areas of:

- Anatomic pathology (e.g. histopathology, cytopathology);

- Clinical microbiology (e.g. bacteriology, virology, immunology and mycology);

- Clinical biochemistry (e.g. enzymology, toxicology and endocrinology);

- Haematology (e.g. blood coagulation tests);

- Cytology (e.g. cervical smear or PAP tests);

- Genetics (e.g. cytogenetics).

Clinical and other functional tests focus on specific organs and require additional technology to measure activity and are usually linked to medical specialties cardiovascular: e.g. electrocardiographic diagnosis; allergy: e.g. allergy test, food sensitivity tests; audiology, etc. Other diagnostic services include tests such as electrocardiographic diagnosis and effort assessment.

The operation of banks for blood, semen, embryo, tissue and transplant organs, including the storing and cataloguing of available specimens, the matching of donated specimens and potential recipients, etc., are classified as part of ancillary services, whether or not they are free-standing areas. These services are not typically independent but components of a health care package, and thus are usually intermediate consumption goods and services. By convention in SHA, their value is not disaggregated: final consumption includes the value of the intermediate consumption components. Here, they should be recorded only if they relate to direct consumption.

\section{HC.4.2 Imaging diagnosis}

This item comprises a variety of services that employ imaging technology, such as $\mathrm{X}$-rays and radiation for the diagnosis and monitoring of patients. The class includes an array of imaging technologies to diagnose and treat diseases, such as:

- Plain X-ray, bone and soft tissue imaging;

- Contrast X-rays or photo-imaging;

- Diagnostic ultrasound;

- Computed tomography (CT);

- Computer-assisted tomography (CAT);

- Nuclear medicine;

- Nuclear magnetic imaging; nuclear scanning;

- Positron emission tomography (PET);

- Magnetic resonance imaging (MRI);

- Other miscellaneous diagnostic imaging (arteriography using contrast material, angiocardiography, phlebography, thermography, bone mineral density studies).

\section{HC 4.3 Patient transportation}

This item comprises the transportation of patients to a health care facility on medical recommendation or as a necessary inter-facility transfer to complement a package of health care services. Examples are emergency transportation to a hospital and transfer between health facilities for additional imaging diagnosis or rehabilitative treatment. The transportation can be delivered in a specially-equipped surface vehicle or in a designated air or water ambulance and takes place to and from facilities for the purposes of receiving 
medical and surgical care. It also includes transportation in conventional vehicles, such as a taxi, when justified by medical recommendation and there is a transaction involved e.g. in the case of an inter-hospital diagnosis imaging procedure. The boundary should correspond to the criteria set out in Chapter 4.

The transport service may be specialised and may or may not involve resuscitation equipment or medical personnel. It can be billed as part of the related benefits (e.g. imaging diagnosis, etc.).

- Includes: all types of transportation services through any means as long as they fit the purpose criteria, e.g. emergency transport services of public fire rescue departments or defence departments that operate on a regular basis for civilian emergency services (not only for catastrophe medicine) are included.

- Excludes: transport costs of accompanying persons, except when the patient is dependent. See Chapter 12 regarding transport costs of travelling abroad for health care.

\section{HC.5 Medical goods (non-specified by function)}

Medicines and other medical goods are frequently a component of a package of services with a preventive, curative, rehabilitative or long-term care purpose. In inpatient, outpatient and day care consumption, they are not usually identified separately, except possibly at a more detailed level.

Medical goods can also be consumed as a result of being prescribed as part of a health care contact or independently in the case of self-prescription. Dispensing may take place within a health care establishment, such as a hospital, or by a free-standing retailer of medical goods. However, the diversification of distribution channels has increased the need to recognise the mixed role of independent consumption within the various modes of health care provision in many countries. The diversity of distribution mechanisms is shown in Figure 5.4. In particular, in many low- and middle-income countries, due to the lack of availability of medicines, both in hospitals and outpatient units, often the relatives or patient need to purchase medicines themselves. This category aims to include all consumption of medical goods where the function and mode of provision is not specified.

Figure 5.4. Distribution mechanisms of medicines

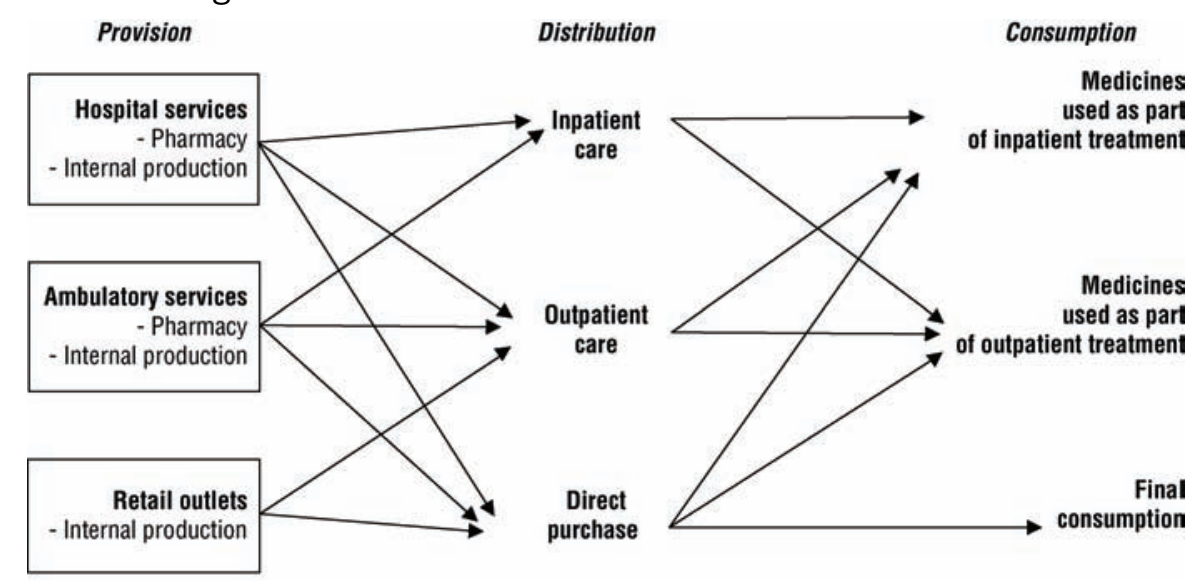

Source: IHAT for SHA 2011. 
- Includes: medical goods acquired by the beneficiary either as a result of prescription following a health system contact or as a result of self-prescription.

- Excludes: medical goods consumed or delivered during a health care contact that are prescribed by a health professional.

- Clarifying cases: as medical goods do not conform to a health purpose in themselves, they should be included as far as possible in the purpose to which they pertain, e.g. in the case of anti-malaria bed nets, they should be accounted for within the malaria programme when they are distributed during malaria interventions. Because their use is only preventive, they should in theory be allocated to prevention. However, by convention they are recorded in HC. 5 when consumers acquire them from retail sellers, because the purpose is not usually identified.

Medical goods are broken down at the second level into pharmaceuticals and other medical non-durables (HC.5.1) and therapeutic appliances and other medical goods (HC.5.2).

\section{HC.5.1 Pharmaceuticals and other non-durable goods}

This comprises pharmaceutical products and non-durable medical goods intended for use in the diagnosis, cure, mitigation or treatment of disease. This includes medicinal preparations, branded and generic medicines, drugs, patent medicines, serums and vaccines, and oral contraceptives. Fluids required for dialysis, as well as gases used in health care, such as oxygen, should also be included when the patient or relatives purchase them directly. This class is further divided into the following sub-classes:

HC.5.1.1 Prescribed medicines. Comprises all pharmaceuticals, including branded and generic pharmaceutical products, which are provided in response to a prescription issued by a licensed medical practitioner or pharmacist.

HC.5.1.2 Over-the-counter drugs (OTC). Comprises all pharmaceuticals, including branded and generic pharmaceutical products which may or may not be available without prescription but have been purchased independently. Inclusions on this category should be linked to the health purpose. ${ }^{28}$

HC.5.1.3 Other medical non-durable goods. Includes adhesive and non-adhesive bandages, hypodermic syringes, first-aid kits, hot-water bottles and ice bags, medical hosiery items such as elastic stockings and knee supports, condoms and other mechanical contraceptive devices. This sub-category also includes medical non-durable goods that have been prescribed by a licensed medical practitioner.

All goods acquired by a patient, regardless of whether purchased in an independent pharmacy or a pharmacy within a medical establishment, hospital or ambulatory setting, or through any other distribution channel, are to be included.

Further breakdowns may also be of interest (and these may evolve subsequently into sub-categories), such as branded and generic medicines and hospital own-manufactured supply. Sub-categories such as "essential medicines" are operational distinctions that are already institutionalised in some countries for routine monitoring, which could be also included in a detailed breakdown. Eventually, a therapeutic breakdown based on the Anatomic Therapeutic Chemical Classification may also be feasible. For some countries the relevant split could involve procurement. A detailed compilation would be required to establish appropriate price and volume indices. ${ }^{29}$ 
- Excludes: veterinary products; articles for personal hygiene, such as medicinal soaps.

- Clarifying cases: TCAM medical goods should be included, except those products not identified as medical goods, such as "healthy food". See Table 4.1 of Chapter 4 on borderline cases for further guidance.

\section{HC.5.2 Therapeutic appliances and other medical goods}

This item comprises a wide range of medical durable goods, such as:

- Orthotic devices that support or correct deformities and/or abnormalities of the human body, e.g. corrective eye-glasses and contact lenses, hearing aids, orthopaedic appliances such as orthopaedic shoes, orthopaedic braces and supports, surgical belts, trusses and supports;

- Prostheses or artificial extensions that replace a missing body part, e.g. artificial limbs and other prosthetic devices, including implants: an implant is a medical device made to replace (or supplement the functionality) of a missing biological structure;

- A variety of medico-technical devices such as powered and unpowered wheelchairs and invalid carriages, "special" beds, and electronic and other devices for monitoring blood pressure.

Therapeutic appliances can be further identified by type at a third-digit level:

HC.5.2.1 Glasses and other vision products. Glasses and other vision products should have a health purpose. This item comprises corrective eye-glasses and contact lenses as well as the corresponding cleansing fluid and the fitting by opticians.

- Excludes: sunglasses not fitted with corrective lenses.

HC.5.2.2 Hearing aids. This item comprises all kinds of removable hearing aids (including cleaning, adjustment and batteries).

- Excludes: audiological diagnosis and treatment by physicians (HC.1.3); hearing implants (HC.1, curative care); and audiological training (HC.1.3).

\section{HC.5.2.3 Other orthopaedic appliances and prosthetics (excluding glasses and hearing}

aids). This item comprises orthopaedic appliances and other prosthetics: orthopaedic shoes, artificial limbs and other prosthetic devices, orthopaedic braces and supports, surgical belts, trusses and supports, neck braces.

- Excludes: glasses and vision products (HC.5.2.1) and hearing aids (HC.5.2.2).

- Clarifying cases: implants with a non-health primary purpose, e.g. aesthetic use, should be excluded. Canes for the blind and dogs for the blind should be included.

HC.5.2.9 All other medical durables including medical technical devices. This item comprises a wide variety of medico-technical devices, such as wheelchairs (powered and unpowered) and invalid carriages, as well as miscellaneous durable medical products not elsewhere classified such as blood pressure instruments. In this class, household final consumption involves the acquisition of consumer durables, meaning goods that may be used for health primary purposes of consumption repeatedly or continuously over a period of a year or more (SNA 2008, 9.42).

- Includes: specialised telematic equipment for emergency calls from the patient's home and/or for the remote monitoring of medical parameters. 
- Excludes: protective goggles, belts and supports for sport. Household improvements are to be accounted for as investment: automatic staircase lifts for patients with mobility limitations; bathtub lifts and similar devices for adapting the housing situation of patients with transitory or chronic impairments, and hire of therapeutic equipment. For information on whether the fixed equipment described here is to be accounted as capital formation or current expenditure see Chapter 11.

- Clarifying cases: see Table 4.1 of Chapter 4 for particular borderline cases.

\section{HC.6 Preventive care}

Prevention is any measure that aims to avoid or reduce the number or the severity of injuries and diseases, their sequelae and complications (Pomey et al., 2000). Prevention is based on a health promotion strategy that involves a process to enable people to improve their health through the control over some of its immediate determinants. This includes a wide range of expected outcomes, which are covered through a diversity of interventions, organised as primary, secondary and tertiary prevention levels.

- Primary prevention involves specific health measures aimed at avoiding diseases and risk factors in order to: reduce the onset of a disease, diminish the number of new cases, and anticipate the emergence and lessen the severity of diseases. The goal of primary preventive measures is the reduction of risks before they generate some effect, e.g. via vaccination.

- Secondary prevention involves specific interventions aimed at the detection of disease and then therapy as early as possible, e.g. via screening. Secondary prevention thereby increases opportunities for less costly and invasive interventions in order to prevent the progression of the disease and the emergence of symptoms, or the "stock of illness". ${ }^{30}$ Examples include screening for diseases such as TB, diabetes and breast cancer. One characteristic of secondary prevention is that it occurs before the diagnosis has been made. Often these early case detections involve laboratory and imaging services.

- Tertiary prevention aims at reducing the negative impact of an already established disease or injury by an attempt to avoid worsening and complications, such as early surgery on a joint damaged by burns. In this example, a tertiary prevention would involve reconstructive surgery to allow for full extension and movement recovery of the joint.

In SHA 2011, preventive care (HC.6) is limited to primary and secondary prevention. Once a diagnosis has been made, a therapeutic or tertiary preventive path is established. The rationale for excluding tertiary prevention is that it overlaps with the curative and rehabilitative purposes, which are aimed at reducing disease-related complications.

\section{Boundary-setting considerations}

The determinants of health involve a wide range of factors and action mechanisms. To set the health care accounting boundary, the criteria presented in Chapter 4 have to be considered; once the health care boundary has been established, the primary purpose principle should then be applied to set the functional classes. This is important to keep in mind because the intervention of the multiple determinants of health can also involve many different purposes. A classic example is education, which intervenes directly and indirectly in many risk-health status mechanisms. However, general education, rather than specific health-related education, has such a significant role that it constitutes a 
purpose in its own right; thus it does not comply with the boundary criteria and so is not included within the health accounting boundary.

The primary purpose of "health promotion" is key to defining the boundary, notably because health determinants often have a social and economic primary purpose. The same risks can be the subject of a social control policy with an economic or safety purpose, and thus not a health purpose. The health boundary for "preventive services" is defined as having the primary purpose of risk avoidance, of acquiring diseases or suffering injuries, which can frequently involve a direct and active interaction of the consumer with the health care system. The spectrum of factors to be considered is wide, but the type of services included in the health prevention boundary is restricted to those components with a primary health purpose. Interventions that go beyond the health care boundary but are policy relevant can be reported as health care-related items.

Some examples of these boundary issues are preventive interventions to avoid immediate risks, such as:

- IEC (health information, education and communication) messages with a health focus regarding substance abuse and alcohol consumption, e.g. special warnings to pregnant women about the secondary effects of overconsumption, as well as information about appropriate healthy behaviour related to diet, smoking and sedentary life styles and about self-protection to avoid injuries due to road accidents. These messages would be prepared by communication experts and disseminated in mass media health campaigns.

- Monitoring and surveillance of health risks and disease control programmes, notably related to risks prevalent in a country, e.g. the gathering of epidemiological information by health offices to analyse trends in diseases and disease risks. It also involves the laboratory testing of the quality of human drinking water, food-borne risks and the personal monitoring of persistent organic pollutants ${ }^{31}$ in the breast milk of women living in risk areas.

These are examples of components within the boundary of health expenditure. However, part of the control of alcohol abuse, road safety and environmental control interventions can be made with a primary purpose that is not health, but rather social and/or economic, e.g. the design of roads, the enforcement of traffic regulation, etc. Any interventions that do not have a primary health purpose lie outside the health care accounting boundary, ${ }^{32}$ as further explained in the following examples:

The environmental field in the economy has a primary focus on all elements, factors and conditions that have some impact on growth and development, on ensuring sustainability and on lowering risks to society. Policy development involves legal as well as technical content. The relevance of particular environmental policies to health is clear in general. However, not all policy formulation has a primary health purpose, nor does its implementation usually have the immediate purpose of improving health. Excluded are all services whose primary purpose is linked to the collection, treatment and remediation of environmental risks. Included within the health boundary are environmental health components that are part of specific health regulations (under HC.7). Also included are the monitoring and surveillance of demonstrated environmental risks with a health purpose, in particular geographical areas that are part of early case detection (HC.6); IEC on environmental health issues, such as warnings about risk exposure during pregnancy (HC.6); and the treatment of environmental effects to reduce the sequelae and damage in affected human groups, through curative health care (HC.1). 
Public safety involves the prevention of, and protection from, events and factors that might endanger the safety of the general public and cause injury, harm or damage. Interventions where health does not represent the main focus are excluded from the health care boundary. Examples of excluded cases include: preventing crimes and disasters (natural or man-made) through the use of specific non-health system interventions; ensuring the safety of transportation systems, roads and the social behaviour associated with them; and to police, fire and disaster fields where health does not represent the main focus. Also excluded are interventions through the criminal justice system that seek to prevent, control and manage the risk of injuries, through legal, judicial, police and other sector interventions focused on weapons, drugs and violence control. These interventions have a purpose that goes beyond health care, although it is relevant to health care. Included as health care components are: IEC measures to prevent injuries caused by individuals and to reduce drug and alcohol consumption among young people and pregnant women (HC.6). Also included are programmes to guide health services during epidemics and disasters (HC.6), and the treatment within the curative health care system of cases that arise due to public safety risks (HC.1).

Transport services. Transportation and traffic policies that involve a primary focus on transportation, but which are related but external to health prevention, are excluded, as they lie outside of the health boundary. Compliance with regulations may involve a nonhealth purpose, e.g. to avoid a fine. Thus, the implementation of such measures is counted neither as health nor as prevention. Included: IEC components that promote healthy behaviour on transportation (HC.6), e.g. information and programmes to promote self-care by the use of crash helmets. Also included are epidemiological studies on injuries and accidents to inform health programmes, e.g. studies on setting the legal limits for blood alcohol levels while driving (HC.6). ${ }^{33}$

\section{Second-digit preventive classes}

The design of preventive programmes target at-risk population groups. These may be based on age, sex or income level; or groups of risks based on people's environment, such as the roadway, home, workplace or residential area. Thus, selected individuals or groups of individuals exposed to similar risks are targeted by preventive programmes to help them to avoid these risks or to detect specific conditions at an early stage. Although some risks are related to specific health conditions, the same or similar types of risks may lead to various health conditions, thus overlaps may exist in the coverage of programmes, depending on their structure at the national level. The structure of the programmes reflects the epidemiological and operational conditions in the country; for example, HIV/AIDS may represent a distinct programme or be part of a joint programme with malaria and tuberculosis or be a component of an overall programme on communicable diseases.

The prevention classification in SHA 2011 is based on the type of services. ${ }^{34}$ As in other classifications, countries with more detailed analytical needs are able to generate breakdowns according to their national characteristics. When doing so, labels should be explicit about the programmes contained and about any comprehensive metadata provided so as to allow international comparison of categories. The classes by type of service have a strategic focus more than a disease focus, which can be obtained through ICD classes in the distribution by beneficiary (see Chapter $10^{35}$ ). To ensure continuity of reporting, SHA 1.0 classes have been kept as memorandum items. 
Prevention may in most cases generate positive externalities. This is clear in communicable diseases and in environmental classes as well as in non-communicable diseases. Examples include waterborne diseases such as cholera; food-borne diseases such as agro-toxics and other biological and non-biological contaminants; and airborne diseases related to PM10 (particulate matter ${ }^{36}$ ) and indoor pollutants.

The breakdown of prevention involves the following classes:

\section{HC.6.1 Information, education and counselling programmes}

Information, education and communication (IEC) combines strategies, approaches and methods to enable individuals, families, groups, organisations and communities to play active roles in achieving, protecting and sustaining their own health. Embodied in IEC is a process of learning that empowers people to make decisions, modify behaviours and change social conditions, including through improvements in knowledge, beliefs, attitudes, use and interaction with the health system. This is a key component of the strategy to overcome organisational and communication barriers to using the health system. The focus is on primary and secondary prevention. This covers individual as well as collective consumption, delivered through a variety of formats, such as mass media and personal advice. This can vary according to the consumer's cultural characteristics. This expenditure may involve information dissemination as well as the time and skills of the specialised personnel providing the advice.

Information and counselling programmes are usually part of control programmes, in which case they are disease-oriented, informing individuals about specific health problems, their conditioning factors and their particular risks. They can be related to risk avoidance strategies, self-protection, medication adherence, self-management guidelines for diseases, pre-operative education, or discharge plans. They can also be related to self-applied tests to monitor health conditions, orienting individuals on how to stay well if the results are negative, and orienting and referring them for follow-up, if positive. Examples include information about the health consequences of smoking, diet, physical activity or salt consumption; special warnings to pregnant women about drug abuse and alcohol consumption; information on risk protection effectiveness through the use of crash helmets and seat belts; and information on vaccination or screening programmes.

\section{HC.6.2 Immunisation programmes}

In order to prevent the development of a disease, before or after exposure, through the use of pharmaceutical products, such as vaccines. This is primary prevention. It can involve consumption by specific individuals in a campaign or in continued programme operations. Examples include immunisation for diphtheria, hepatitis, herpes zoster, HPV, influenza, measles, meningococcal infections, mumps, pertussis (whooping cough), pneumococcal infections, polio, rabies, rubella, tetanus, varicella (chicken pox) and yellow fever. The expenditure involved in the consultation, both for the time and skills of the personnel and the purchase of the vaccine itself, should be accounted for.

\section{HC.6.3 Early disease detection programmes ${ }^{37}$}

This item concerns the active search for a disease early in its course, before symptoms appear, within the risk groups, as organised programme activities. This can involve screening, diagnostic tests and medical examinations. These are directed to specific 
diseases, such as breast cancer, cervical cancer, colon rectal cancer, diabetes, HIV/AIDS, malaria, tuberculosis, prostate cancer and so on. According to the criteria set for prevention, it would involve only early disease detection before a diagnosis is made. According to the boundaries of health care, a self-examination performed without a transaction involved would not be accounted for. Self-examination can generate expenditure when it involves the purchase of tests to be self-performed, e.g. levels of sugar in blood or urine, which are to be reported as HC.5. Control and follow-up exams after diagnosis should be considered as part of curative care (HC.1).

\section{HC.6.4 Healthy condition monitoring programmes}

This item concerns the active monitoring of healthy conditions and is not focused on specific diseases. These can target specific conditions such as pregnancy (antenatal and postnatal care) or specific age groups such as children (e.g. child growth and development) or ageing groups, or specific health domains, such as dental and general health check-ups.

\section{HC.6.5 Epidemiological surveillance and risk and disease control programmes}

This class involves technical operations to manage knowledge and resources with a preventive and control focus. This is done through the planning, monitoring and evaluation of interventions, including measures to inform decision-making, such as accessing information and support services. This includes information systems related to epidemiology and health and management to track cases, records and health system responses; ${ }^{38}$ support measures such as operational activities aimed at immediate improvement of the programme; and hands-on training and operational research. ${ }^{39}$

The generic content includes ${ }^{40}$ : conducting surveillance of outbreaks and patterns of communicable and non-communicable diseases and of injuries and exposure to environmental agents harmful to health, as well as investigating appropriate responses. ${ }^{41}$ Examples include: epidemiological surveillance and research by health systems to identify and diagnose cases; the measurement of selected health conditions and diseases with a community impact, such as tuberculosis; analysis of the accuracy of health records and information systems; monitoring samples of human drinking water and food in relation to water and food-borne disease; epidemiological studies of other environmental risks, such as testing human breast milk in areas at risk for persistent organic pollutants (POP); hands-on training to ensure that procedures and treatment protocols set for the various health programmes are followed; and overcoming barriers to the access of health services by individuals and population groups. This includes the appropriate assessment of programme operations so as to identify required operational improvements related to any health system component, such as the schedule of delivery of services, information to users, and the analysis of coverage of the delivery area by health establishments.

Records on expenditures for this class are usually linked to the technical areas organising the preventive programmes with a collective approach, e.g. HIV/AIDS, tuberculosis and cancer programmes, etc. Thus they may be available from technical and co-ordination areas that are related to programme components not directly involved in the operation of health care services, such as the Ministry of Health, district and regional offices, NGOs and so on. See Chapter 14 on accounting rules for more detail on the selection of allocation keys to apportion expenditure. 
Table 5.2. Preventive and public health components in SHA $\mathbf{1 . 0}$ and SHA 2011

\begin{tabular}{|c|c|c|c|c|c|c|c|}
\hline Content: mostly as described in SHA 1.0 & $\begin{array}{c}\text { Programme } \\
\text { Code SHA } 2011\end{array}$ & $\begin{array}{l}\text { New } \\
1 \text { item }\end{array}$ & $\begin{array}{l}\text { Programme } \\
\text { Code SHA } 1.0\end{array}$ & $\begin{array}{l}\text { Content: mostly as described } \\
\text { in SHA } 1.0\end{array}$ & $\begin{array}{c}\text { Programme } \\
\text { Code SHA } 2011\end{array}$ & $\begin{array}{l}\text { New } \\
\text { item }\end{array}$ & $\begin{array}{l}\text { Programme } \\
\text { Code SHA } 1.0\end{array}$ \\
\hline $\begin{array}{l}\text { Maternal and child health; family planning } \\
\text { and counselling }\end{array}$ & & & HC.6.1 & $\begin{array}{l}\text { Prevention of non-communicable } \\
\text { diseases }\end{array}$ & & & HC.6.4 \\
\hline Genetic counselling & HC.6.1 & & HC.6.1 & Health education & HC.6.1 & & HC.6.4 \\
\hline Identification of genetic abnormalities & HC.6.3 & & HC.6.1 & Disease prevention & HC.6 & & HC.6.4 \\
\hline Prenatal and postnatal medical care & HC.6.4 & & HC.6.1 & Health promotion & HC.6. & & HC.6.4 \\
\hline Baby health care & HC.6.4 & & HC.6.1 & Programmes of risk avoidance & HC.6.1 & & HC.6.4 \\
\hline Pre-school and school child health & HC.6.4 & & HC.6.1 & $\begin{array}{l}\text { Improvement of health status not } \\
\text { directed specifically towards } \\
\text { communicable disease }\end{array}$ & HC.6.4 & & HC.6.4 \\
\hline $\begin{array}{l}\text { Programme design, monitoring and } \\
\text { evaluation }\end{array}$ & & HC.6.5 & & $\begin{array}{l}\text { Interventions against smoking, } \\
\text { alcohol and substance abuse }\end{array}$ & HC.6.1 & & HC.6.4 \\
\hline $\begin{array}{l}\text { Regulation linked to basket of services and } \\
\text { population coverage on } \mathrm{MCH} \text {, FP }\end{array}$ & & HC.7.1 & & Activities by community workers & HC. 6 & & HC.6.4 \\
\hline School health services & & & HC.6.2 & $\begin{array}{l}\text { Services provided by self-help } \\
\text { groups }\end{array}$ & HC.6.1 & & HC.6.4 \\
\hline Education & HC.6.1 & & HC.6.2 & $\begin{array}{l}\text { General health education and health } \\
\text { information }\end{array}$ & HC.6.1 & & HC.6.4 \\
\hline Screening & HC.6.3 & & HC.6.2 & Health education campaigns & HC.6.1 & & HC.6.4 \\
\hline Disease prevention & HC. 6 & & HC.6.2 & $\begin{array}{l}\text { Campaigns in favour of health } \\
\text { promotion (life style, sex, etc) }\end{array}$ & HC.6.1 & & HC.6.4 \\
\hline Health promotion & HC. 6 & & HC.6.2 & $\begin{array}{l}\text { Information exchanges (alcoholism, } \\
\text { drug addiction) }\end{array}$ & HC.6.1 & & HC.6.4 \\
\hline $\begin{array}{l}\text { Basic medical treatment (including dental } \\
\text { care) }\end{array}$ & HC.1 & & HC.6.2 & $\begin{array}{l}\text { Public health environmental } \\
\text { surveillance }\end{array}$ & HC.6.5 & & HC.6.9 \\
\hline $\begin{array}{l}\text { Interventions against smoking, alcohol and } \\
\text { substance abuse (in school) }\end{array}$ & HC.6.1 & & HC.6.2 & $\begin{array}{l}\text { Public information on environmental } \\
\text { conditions }\end{array}$ & HC.6.1 & & HC.6.9 \\
\hline Vaccination programmes & HC.6.2 & & HC.6.3 & $\begin{array}{l}\text { Programme design, monitoring and } \\
\text { evaluation }\end{array}$ & & HC.6.5 & \\
\hline $\begin{array}{l}\text { Programme design, monitoring and } \\
\text { evaluation }\end{array}$ & & HC.6.5 & & $\begin{array}{l}\text { Regulation linked to basket of } \\
\text { services and population coverage on } \\
\text { non-communicable diseases }\end{array}$ & & HC.7.1 & \\
\hline $\begin{array}{l}\text { Regulation linked to basket of services and } \\
\text { population coverage on school health }\end{array}$ & & HC.7.1 & & Occupational health care & & & HC.6.5 \\
\hline Prevention of communicable diseases & & & HC.6.3 & Surveillance of employee health & HC.6.4 & & HC.6.5 \\
\hline $\begin{array}{l}\text { Compulsory reporting and notification of } \\
\text { diseases }\end{array}$ & HC.6.5 & & HC.6.3 & Routine medical check up & HC.6.4 & & HC.6.5 \\
\hline $\begin{array}{l}\text { Epidemiologic enquiries of communicable } \\
\text { diseases }\end{array}$ & HC.6.5 & & HC.6.3 & $\begin{array}{l}\text { Therapeutic care, including } \\
\text { emergency services }\end{array}$ & HC.1 & & HC.6.5 \\
\hline Trace contacts and origin of disease & HC.6.5 & & HC.6.3 & Ergonomy, safety & $\begin{array}{l}\text { HC. } 6 \\
\text { (health part) }\end{array}$ & & Excluded \\
\hline Prevention of tuberculosis & HC. 6 & & HC.6.3 & $\begin{array}{l}\text { Health and environmental protection } \\
\text { at work }\end{array}$ & $\begin{array}{l}\text { HC. } 6 \\
\text { (health part) }\end{array}$ & & Excluded \\
\hline Tuberculosis control (screening) & HC.6.5 & & HC.6.3 & Accident prevention at work & $\begin{array}{l}\text { HC.6 (health } \\
\text { part) }\end{array}$ & & Excluded \\
\hline $\begin{array}{l}\text { Immunization/vaccination (compulsory and } \\
\text { voluntary) }\end{array}$ & HC.6.2 & & HC.6.3 & $\begin{array}{l}\text { Programme design, monitoring and } \\
\text { evaluation }\end{array}$ & & HC. 6.5 & \\
\hline Vaccination under maternity and child care & HC.6.2 & & HC.6.3 & $\begin{array}{l}\text { Regulation linked to basket of } \\
\text { services and population coverage on } \\
\text { occupational health }\end{array}$ & & HC.7.1 & \\
\hline Vaccination for occupational health & HC.6.2 & & Exc HC.6.5 & $\begin{array}{l}\text { All other miscellaneous public } \\
\text { health services }\end{array}$ & & & HC.6.9 \\
\hline $\begin{array}{l}\text { Vaccination for travel and tourism on } \\
\text { patient's initiative }\end{array}$ & HC.1 & & HC.1 & $\begin{array}{l}\text { Operation and administration of } \\
\text { blood and organ banks }\end{array}$ & HC.4.1.2 & & HC.6.9 \\
\hline $\begin{array}{l}\text { Programme design, monitoring and } \\
\text { evaluation }\end{array}$ & & HC.6.5 & & $\begin{array}{l}\text { Public health environmental } \\
\text { surveillance }\end{array}$ & HC.6.1 & & HC.6.9 \\
\hline $\begin{array}{l}\text { Regulation linked to basket of services and } \\
\text { population coverage on communicable } \\
\text { diseases }\end{array}$ & & HC.7.1 & & $\begin{array}{l}\text { Public information on environmental } \\
\text { conditions }\end{array}$ & HC.6.1 & & HC.6.9 \\
\hline
\end{tabular}

Source: IHAT for SHA 2011. 


\section{HC.6.6 Preparing for disaster and emergency response programmes}

Includes preparations for an appropriate response in case of humanitarian emergencies, whether of human or natural origin. The aim is to protect health and to reduce mortality and morbidity due to health hazards through in particular field epidemiology as well as training in technical standards. This would involve e.g. the capacity to acquire or expand resources very quickly, and preparations for changing the handling and referencing of patients, such as patient triage and restructuring coverage in line with the nature of the emergency.

This class can be adjusted to country-specific needs, as the health risks can vary in different areas. However, in all cases health rules and a health infrastructure should be prepared to cope with emergency health care needs.

\section{HC.7 Governance, and health system and financing administration}

These services focus on the health system rather than direct health care, and are considered to be collective, as they are not allocated to specific individuals but benefit all health system users. They direct and support health system functioning. These services are expected to maintain and increase the effectiveness and efficiency of the health system and may enhance its equity.

These expenditures are incurred mostly but not exclusively by governments. Included are the formulation and administration of government policy; the setting of standards; the regulation, licensing or supervision of producers; management of the fund collection; and the administration, monitoring and evaluation of such resources, etc. However, some of these services are also provided by private entities, including by civil society (NGOs) and private medical insurance. Clear examples of such civil participation are health advocacy, health observatories and health user/consumer associations.

\section{HC.7.1 Governance and health system administration}

Although these cover more than a single function, one class is proposed at the seconddigit level due to its relatively low share of spending and the difficulty in distinguishing it.

Governance $^{42}$ has been defined as "the careful and responsible management of the well-being of the population" (WHO, 2003), and comprises three broad tasks: providing vision and direction, collecting and using intelligence and exerting influence through regulation and other means. It includes planning, policy formulation and information intelligence for the entire health system, such as:

- The monitoring of health needs (WHO, 2002, EPHF 1) and health care interventions;

- Health accounting and specific resource monitoring (EPHF 6) and auditing;

- Development of policies and planning (EPHF 3);

- Health promotion partnerships, social participation and empowerment (EPHF 7);

- Research, development and implementation of innovative interventions to set standards (EPHF 9).

SHA 2011 includes in this category the general public service component, which is part of the government function through the overall planning and statistical services (as expressed in COFOG 01.3).

Administration involves a management focus, including to design regulatory measures, to generate incentives, and to control organisations and resources in the 
system, such as general and specialised medical establishments, including dental services, hospitals and clinics, nursing and convalescent home services and independent practices. Directive and operational roles as well as the resources involved in such operations are to be included.

- Strategic management of health systems and services to improve the population's health;

- Regulation to protect public health, including accreditation and quality assurance;

- Human resources development and planning.

Excludes: any overhead expenses connected with the administration or functioning of health providers, including hospitals or other providers, which are to be included in the expenditures by service consumed (HC.1-HC.6). For example, if a group of public or private hospitals has a central unit that provides certain common services, such as purchasing, laboratories, ambulances, or other facilities, the value of these common services would be taken into account as part of the value of those individual services.

Clarifying cases: the regulatory function is part of the governance function and includes the setting of modalities to enforce regulations. However, each programme's technical board has the responsibility to ensure enforcement at the operational level. Thus the formulation of regulations and their enforcement mechanisms are part of governance, and the implementation of regulatory enforcement within specific programme controls is part of the relevant function. The operational level is likely to be separable through specific programme-focused bodies.

\section{HC.7.2 Administration of health financing}

This class involves a subcomponent specific to health financing, regardless of its public and private origin or its public and private provision, e.g. budgeting and fundraising (Poullier, 1992; Nicolle and Mathauer, 2010). It contains the management of the collection of funds and the administration, monitoring and evaluation of such resources. Among the specific services linked to resource mobilisation are the identification of members of the schemes; their enrolment; the billing and collection of contributions; and the management of exemptions. Within the pooling function, risk equalisation is one important service. As for the purchasing function, the services included are selecting, negotiating, purchasing and contracting with health providers, as well as the claims processing system, which includes gate-keeping, making payments to providers, and patient reimbursement.

A further optional split at the third-digit level is proposed by public and private financing schemes.

Administration of private health insurance essentially means the health insurance service and the service charge ${ }^{43}$ for this. This covers expenditure on sales, enrolment and policy service, claim adjudication, actuarial functions, legal support services, investment functions, corporate overheads and risk charges.

For public agencies it is expected to also involve the administrative costs of Federal, State and local government health programmes.

Excludes: the administrative costs of the health providers and the health care goods and services they provide. Also excluded are the opportunity costs of paperwork for consumers and the associated general revenue tax collection. 


\section{HC.9 Other health care services not elsewhere classified (n.e.c)}

This item includes any other health care services not classified in HC.1 to HC.7.

\section{HC.RI Reporting items}

\section{HC.RI.1 Total pharmaceutical expenditure (TPE)}

Pharmaceuticals are one of the most frequently used technological products for all health care purposes. Total pharmaceutical expenditure has been estimated to constitute around one-third of current health expenditure. However, the consumption may follow different paths; for example, those typically used as part of an inpatient contact are included as intermediate consumption and thus not accounted for independently. The functional classification accounts only for the direct purchase of medical goods by consumers in retail sales (HC.5), regardless of whether or not it is the result of a contact with the health system. A further sub-classification allows the identification of the prescribed consumption (HC.5.1.1). Pharmaceutical policies require information on the total pharmaceutical consumption expenditure as well as the various channels, prices, composition, etc. A comprehensive measurement of the pharmaceutical consumption is of major relevance in a health care functional approach.

An estimate of total pharmaceutical consumption expenditure is important for planning and decision-making. The total figure for expenditure on pharmaceutical consumption is obtained by adding the explicitly reported part (HC.5.1.1 + HC.5.1.2) and the other components of pharmaceutical consumption regardless of the consumption path. This is the case of the pharmaceutical component within treatment packages, notably as part of the interaction within the contact for curative care (HC.1), which is expected to be the largest amount, but also part of rehabilitative care (HC.2) and long-term care (HC.3). There may also be amounts incorporated as part of outpatient care from prescribing physicians (part of HC.1.3).

Within health facilities, notably those for inpatient care, part of the service may sometimes involve complementary efforts to produce some medicines and to integrate and deliver the "pill boxes". This would imply that the consumption of pharmaceuticals involves not only the cost of the products (directly) purchased but also the cost of the complementary distribution services. To generate an accurate amount, a stepwise approach is recommended, as in other cases. ${ }^{44}$

A further subclass could be inpatient pharmaceutical consumption. Some other partial classes, such as pharmaceuticals under procurement, generics and ATC classes, may also be of interest for national purposes.

\section{HC.RI.2 Traditional, Complementary and Alternative Medicines (TCAM)}

TCAM has been identified as policy relevant in many countries due either to its cultural importance or its high growth rate, both in high- and middle-per capita income countries. Policies related to TCAM are emerging and need to be monitored. Due to the mix of purposes and practices and financing profiles, TCAM systems, therapies and disciplines (including the related medical goods) are a de facto sub-class of hospitals, ambulatory care services and retailers. 


\section{The scope and boundary of traditional, complementary and alternative medicine}

(TCAM). Broadly stated, health care can be divided into modern (mainstream, conventional, orthodox, Western or allopathic ${ }^{45}$ ) and traditional (indigenous, complementary, alternative or integrative), with the division differing across countries.

Non-allopathic care includes all services from any practice that have a health intent but do not fall within the realm of allopathic medicine. The generic term in use is Traditional, Complementary and Alternative Medicines (TCAM). As defined by WHO, "Traditional medicine" is an amorphous concept that comprises a range of long-standing and still-evolving practices based on diverse beliefs and theories. These services involve medical knowledge systems, developed over centuries within various societies before or during the development of modern medicine. "Complementary and alternative" services are those that are used together with or instead of allopathic health care but which are not yet incorporated into the established international medical system, even when at national level they are extensively used.

$\mathrm{TCAM}^{46}$ are common in most countries and prevalent in countries representing more than half of the world's population (WHO, 2005b; Bodeker et al., 2005). The reporting of TCAM does not contravene the legislative and regulatory control advocated in countries where allopathic medicine is the dominant form. The TCAM class is included in the functional (HC) classification to describe, monitor, analyse and classify financing flows, related resource mobilisation, the use of production factors and consumption patterns. TCAM is intrinsically challenging to monitor because of its linkage to informal markets, notably in the low- and middle-income countries (LMIC). An approach based on effective institutional neutrality is needed to track TCAM in order to ensure the comparability of data between countries. There is a wide diversity within this class, and new practices are continuing to emerge. Differences in TCAM provision between countries therefore complicate the tracking of comparable information. The most common types are summarised as (Kristoffersen et al., 2008):

- Alternative health systems, among which the most disseminated are acupuncture, homeopathy, chiropractics, osteopathy;

- Complementary therapies, such as Alexander therapy, aromatherapy, Bach therapy and other flower therapies, body therapy, Ayurvedic, herbal medicine, naturopathy, nutritional therapy, yoga and spa therapy;

- Alternative disciplines, such as crystal therapy, iridology, kinesiology and radionics;

- Spiritual and esoteric practices.

Essentially, the difference between traditional medicine systems and traditional medicine therapies is in the exhaustiveness of the reach. For example, traditional Chinese medicine is a system that includes the use of Chinese traditional therapies, such as needling, herbal medicines, tuina and so on. Chiropratics is in itself a system and may include therapies such as manual joint manipulation, nutritional therapy and exercise prescription. Herbal medicine, on the other hand, is a therapeutic ingredient that any system can include, when the practitioners are trained to do so.

Spiritual and esoteric components, such as religious and astrological practices, are related to an individual holistic sphere of self for which health knowledge and practice is difficult to identify and isolate from other purposes, e.g. spiritual and esoteric practices to promote well-being, spiritual development, social success or sport or educational performance. Thus, although they are part of the TCAM scope, spiritual and esoteric 
practices are not part of health care components. Some therapies, like yoga, can also be consumed with a well-being purpose, in which case they are also external to the health care boundary (see Chapter 3).

The range of purposes of TCAM services is similar to that observed for allopathic practice:

- Preventive, curative, rehabilitative or maintenance in nature;

- Diagnostic, surgical and prescriptive procedures.

Non-allopathic goods include a huge diversity of products and can be acquired during treatment and from both specialised and non-specialised retailers (WHO, 2005b):

- Types of herbal medicines;

- Prescription medicines: medicines that can be provided only in response to a prescription issued by a licensed medical practitioner or pharmacist;

- Over-the-counter medicines: medicines that may or may not be available without prescription but have been purchased independently;

- Dietary supplements: products intended to increase the total daily intake of a concentrate, a metabolite, constituent, extract or combination of these ingredients; substances that contain, for instance, a vitamin, a mineral, an herb or other botanical element or an amino acid;

- Health food: a food believed to be highly beneficial to health, especially a food grown organically and free of chemical additives. It is regulated differently from other foods;

- Functional foods: foods or food ingredients that have been shown to affect specific functions or systems in the body (e.g. yogurt, which promotes beneficial microflora in the gut).

The primary purpose of food, both healthy and functional, is alimentary, which puts it outside of the health care boundary.

As TCAM lies at the centre of many systems that deal with health by enhancing energy more than by treating each ailment individually, it can be difficult to define a boundary with well-being. This problem is not exclusive to TCAM, but also affects allopathic practices (e.g. recommendations on diet and physical activity for prevention in the cardiovascular field can be difficult to isolate and report).

Although the purpose of TCAM practice is in principle the same as for allopathic practice, some of the components can be difficult to separate from other purposes of consumption, such as well-being in the case of yoga, or alimentary in the case of food products. Measurement is also complex. In many countries, TCAM is integrated with allopathic practice. In the absence of specific records, it is neither identified nor accounted for. SHA 1.0 recommended the exclusion of illegal or non-certified health interventions (SHA 1.0 paragraph 5.15). Social and regulatory stigma reflected in survey and administrative recording should be progressively adjusted so as to improve comparability and reduce the "statistical gap". To sum up, boundaries between TCAM and allopathic practices are not easy to set and monitor, and in practice will be fixed according to national conventions.

The resources needed to produce TCAM estimates are not negligible. Some criteria to produce fairer accountability are:

- Effectiveness. The health benefits of TCAM have so far not been fully assessed in ways that can be universally accepted as being evidence-based. That said, many of the 
procedures and technologies used in allopathic medicine also continue to lack a valid assessment. Moreover, health accounts aim to measure neither the impacts on welfare nor the effectiveness of health services. Thus, the effectiveness criterion is not valid for ranking TCAM.

- Provision. Although TCAM practice has the same purpose as allopathic practice, the technology employed is different and the personnel in charge can have different qualifications. Thus, an analysis by provider (public and private) would also be appropriate to measure expenditure on TCAM. One difficulty already identified is the cohabitation of TCAM and allopathic practices, which may hamper a distinction. Hospitals may have a specific TCAM department, or services may be mixed with allopathic provision. The situation of outpatient offices can be similar. Direct provision by ministerial services can also mix allopathic and non-allopathic services. Thus, in countries with mixed practices, expenditures may be better allocated to specific personnel rather than to facility-type structures. Such a breakdown has already been said to be desirable, e.g. to highlight traditional birth attendants. This could be reflected in the classification of health care providers.

- Qualifications. Within most individual TCAM professions there are defined minimum standards, but many TCAM schools are not yet able to meet these standards due to limited resources. ${ }^{47}$ In spite of the lack of qualifications, such services are expanding and are increasingly socially accepted, and official health care programmes are enlarging the coverage for specific interventions by these practitioners.

- Registration and legislation. In 2010, around two-thirds of WHO Member States still did not have a specific national policy on TCAM, though in more than half of them, regulations were under development. Procedures to register TCAM providers are similar to those for allopathic practitioners. ${ }^{48}$

- Registration of TCAM products. Product registration can also be set in place. For most countries, laws or regulations are the same or partly the same as for conventional pharmaceuticals, but are not yet developed for most functional foods, health foods and herbal medicines; e.g. in South Africa, a list of products has been compiled by technical specialists representing each of the complementary medicine modalities. Substances that have been rigorously tested for safety and efficacy in other parts of the world will not have to be re-tested in South Africa. As long as a product contains substances from accepted pharmacopoeia, at safe dosages, the product will undergo testing to ascertain that it is produced under good manufacturing procedures and to verify the contents (Robinson and Zhang, 2011a). ${ }^{49}$

- Mode of financing should not define TCAM inclusion. Financing schemes or payments for TCAM may not be different from those for allopathic medicine. Current reporting practices already include these classes in most countries without any specific marker, e.g. they are partially reimbursed by public and private insurance schemes and regularly reported as aggregates by those schemes, with acupuncture, spa treatment and chiropractics being the most common.

- Data availability does not represent a criterion to include or exclude TCAM. Household surveys in many countries include questions about these types of consumption and they are reported as part of out-of-pocket payments (OOPS). COICOP (Classification of Individual Consumption by Purpose) includes TCAM explicitly as part of outpatient care (COICOP class 06.2.3 - Paramedical services).$^{50}$ In many countries, household payments may also 
involve in-kind transactions for which a record system may not be set up. Notably, the valuation criteria should be made explicit.

Towards a classificatory scheme for TCAM . Although services are to be classified as a single Reporting item (RI) category, a further breakdown could be made. ${ }^{51}$ Table 5.3 shows TCAM aggregated into MoP major categories.

Table 5.3. TCAM entries as a reporting item class HC.RI.2

\begin{tabular}{ll}
\hline HC.RI.2 & Traditional, Complementary and Alternative Medicines (TCAM) \\
HC.RI.2.1 & Inpatient TCAM \\
HC.RI.2.2 & Outpatient and home based TCAM \\
HC.RI.2.3 & TCAM goods \\
\hline
\end{tabular}

Source: IHAT for SHA 2011.

\section{HC.RI.3. Prevention and public health services (according to SHA 1.0)}

The content of HC.6 Prevention and public health services in SHA 1.0 was organised by either type of programme or beneficiary group or by the setting of consumption. The main problems identified included: a) a potential overlap of classes, depending on the country's programme structure, $b$ ) the inclusion of some curative services and exclusion of some preventive services reported under HC.R 3 and HC.R 4, c) the exclusion of some prevention services that result from an individual initiative, $d$ ) some components of prevention have been difficult to disaggregate from administration, and e) blood banks were reported as public health services.

The classification in SHA 2011 involves the following changes: a) organisation by type of service, $b$ ) a focus on prevention, which allows for a clear boundary setting, c) individual preventive care is excluded and to be reported within HC.1, d) integration of certain health preventive components with an unclear description that were previously allocated under HC.R.3 and HC.R.4, and e) blood banks are relocated as an ancillary service, complementary to preventive, curative or rehabilitative care. The main barrier to reporting prevention that is integrated into curative, rehabilitative or LTC services is the lack of appropriate records. Thus, a clear definition is not yet enough to ensure a comprehensive class of prevention.

As a result, in principle the reported amount on prevention remains close to but different from that of SHA 1.0. The SHA 1.0 classification is therefore retained and a progressive refinement over time is expected. With that aim, Reporting Item (HC.RI.3) equates to HC.6 in SHA 1.0, and is within the boundary of health care. The proposal is to keep them as is, so as to promote a continued reporting practice, notably during the transition to SHA 2011 (see Table 5.2 for a mapping of these categories).

\section{HC.RI.3.1 Maternal and child health; family planning and counselling (according to SHA 1.0)}

Maternal and child health covers a wide range of health care services, such as genetic counselling and the prevention of specific congenital abnormalities, prenatal and postnatal medical attention, baby health care, pre-school and school child health, and vaccinations. 


\section{HC.RI.3.2 School health services (according to SHA 1.0)}

This item comprises a variety of health education and screening services (for example, by dentists), disease prevention, and the promotion of healthy living conditions and lifestyles in the school. This includes basic medical treatment, such as dental treatment, if provided as an integral part of the public health function.

- Includes: interventions against smoking and alcohol and substance abuse.

- Excludes: vaccination programmes (HC.6.1).

\section{HC.RI.3.3 Prevention of communicable diseases (according to SHA 1.0)}

This item comprises the compulsory reporting and notification of certain communicable diseases and epidemiological enquiries into communicable disease; efforts to trace possible contacts and origins of disease; the prevention of tuberculosis and tuberculosis control (including systematic screening of high-risk groups); immunisation/vaccination programmes (compulsory and voluntary); and vaccination under maternity and child health care.

- Excludes: vaccination for occupational health (HC.6.1); vaccination for travel and tourism on the patient's own initiative (HC.6.1).

\section{HC.RI.3.4 Prevention of non-communicable diseases (according to SHA 1.0)}

This item comprises public health services involving health education, disease prevention, and the promotion of healthy living conditions and lifestyles such as services provided by centres for disease surveillance and control, and programmes for the avoidance of risks and the improvement of the health status of nations, even when not specifically directed towards communicable diseases.

- Includes: interventions against smoking and alcohol and substance abuse, such as antismoking campaigns; activities of community workers; services provided by self-help groups; general health education and health information of the public; health education campaigns; campaigns in favour of healthier lifestyles, safe sex, etc.; and information exchanges: e.g. on alcoholism or drug addiction.

- Excludes: public health environmental surveillance and public information about environmental conditions.

\section{HC.RI.3.5 Occupational health care (according to SHA 1.0)}

Occupational health care comprises a wide variety of health services such as surveillance of employee health (routine medical check-ups) and therapeutic care (including emergency health care services) on or off business premises (including government and NPISH). It excludes, however, remuneration-in-kind of health care goods and services that constitute household actual final consumption rather than intermediate consumption of business.

\section{HC.RI.3.9 All other miscellaneous public health services (according to SHA 1.0)}

This item comprises a variety of miscellaneous public health services, such as the operation and administration of blood and organ banks, and the preparation and dissemination of information on public health matters not elsewhere classified.

- Includes: public health environmental surveillance and public information on environmental conditions. 


\section{HCR Health care-related classes}

\section{HCR.1 Long-term care (social)}

This item comprises the expenditure on lower-level social care services to assist with instrumental activities of daily living (such as home-help, meals on wheels, transport and day centres, etc.). As the health care components of long-term care are contained in HC.3, the complementary social components are included as a health care-related category that is further subdivided into in-kind and in-cash components. The health and social care components, HC.3 and HC.R.1, can be summed up to obtain a total value of long-term care (LTC). The social care components of LTC may be provided and remunerated as a package of services along with long-term nursing and personal care services. If such services cannot be separately accounted for, and are not the dominant component of the package, they should be included under HC.3; otherwise the complete package should be under HC.R.1: Long-term care (social).

- Includes: subsidies to residential services (as well as expenditure on accommodation) in assisted living arrangements and other kinds of protected housing for persons with functional limitations (as well as residential services for people who suffer from mental retardation, mental illness or substance abuse problems as well as homes for physically and mentally disabled people); housekeeping services, day-care social services for dependent persons; and transport to and from day-care facilities or similar social services for persons with functional limitations.

- Excludes: all services that are predominantly related to providing long-term health and personal care which are included in the function HC.3: Long-term care (Health). Also excluded are services involving surveillance of persons with mental deficits such as dementia patients, and medical assessment and services involving case management and co-ordination between medical and long-term health care (which are also included under HC.3).

- Excludes also: special schooling for disabled people and vocational rehabilitation.

HCR.1.1 In-kind long-term social care. This item comprises long-term social care services in kind as described above that are provided to persons with health problems and functional limitations or impairments, where the primary purpose is to enable independent living and interaction with the environment.

HCR.1.2 Long-term social care cash-benefits. This item comprises the provision of longterm social care benefits in the form of transfers provided to individual persons and households. It mainly covers informal care services of a social nature provided by family members or the remuneration of formal social support providers to assist in instrumental activities of daily living to enable independent living. It does not cover cash benefits for income protection in the case of sickness or disability, such as paid sickness leave or income protection in the case of disability (other than disability pensions for persons above the retirement age).

\section{HCR. 2 Health promotion with a multi-sectoral approach}

Health is the result of the interaction of a wide range of determinants. To improve health outcomes, health systems as well as global geopolitical, socio-economic, informational, technological and climatic interventions are required. Comprehensive coverage is sought 
for health promotion by including the total expenditure of joint efforts within multisectoral and multi-partner services and programmes that can be of policy relevance. In most cases, the multi-sectoral approach has joint interests, and expenditure that is beneficial to health care may overlap with that of other social functions. The aim of having a multi-sectoral measurement balances the restricted boundaries of health care with responsibility for accountability of the resources underlying the health system, as well as those beyond the health system, involved in health promotion efforts.

The aim of this class is to account for health promotion resources that may go beyond the health care boundary, though nevertheless clearly involved with a health interest.

HCR.2.1 Food and drinking water interventions. This item comprises a variety of activities of a collective health concern, such as the inspection and operation of health regulations covering various industries, notably those linked to food and drinking water for human consumption. The extent to which the content is covered may vary with country practices and needs. Examples include the control of human drinking water and the control of food within the food production and distribution process. The expenditure to be included may refer to communications with technical health officers external to the $\mathrm{MoH}$ and joint interventions with other health promotion agencies, based in particular on the evidence of existing risks associated with water and food safety issues. ${ }^{52}$

- Includes: food and water security measures, such as agro-cultural interventions to avoid toxicological pollution of food and water to be used for nutritional purposes and the enhancement of quality control measures regulating the generation and distribution of food and drinking water products.

- Excludes: expenditure on direct health regulations (HC.7) as well as on the monitoring and surveillance programme components, such as the quality control performed by public health laboratories (HC.6.2).

\section{HCR.2.2 Environmental interventions (excluding those related to food and drinking}

water). This item comprises a variety of environmental control interventions with a specific focus on a public health concern, such as waste management (safety measures connected to these services), waste water management (safety measures and quality norms), pollution abatement (prevention, monitoring, abatement and control of noise and the pollution of air, water bodies and soil), $R \& D$ in environmental protection ( $R \& D$ in public health issues related to environmental protection).

A subclass could be advisable to account for the expenditure on environmental issues related to the health system, such as the destruction of nuclear items, dangerous equipment and supplies.

Excludes: expenditure on direct health environmental regulations (HC.7), as well as on the monitoring and surveillance programme components, such as the monitoring of persistent organic pollutants in human milk in geographic risk areas performed by public health laboratories (HC.6.2).

HCR.2.3 Other multi-sectoral health promotion. This class aims at collecting expenditure that involves a heavy public health interest, but is not necessarily within the health boundaries: this is the case both of the tobacco control initiative, for which some interventions go beyond health, as well as of road safety, where there is a strong interest in injury prevention but which also involves a primary interest in transportation and other 
branches. It would be advisable that each of the components remains labelled and also well documented in the metadata so as to facilitate inter-country comparisons.

Interventions in such a diverse range of areas involve to some extent a systematic approach: strengthening surveillance systems, improving risk assessments, assessing new technologies for safety and risk reduction, enhancing risk communication and advocacy, enhancing the health system role in co-ordinating with other partners, and improving international and national co-operation.

The proposed breakdown for this category is by type of risk:

- Individual behaviour;

- Household risks;

- School risks;

- Work place risks;

- Road risks;

- Urban risks.

\section{Notes}

1. However, there is no intuitive global understanding of the term "function". In national accounts, this can refer to groups of goods and services or products, to the primary purpose of institutional units, to the purpose of the activities of production units or even to the purpose of financing.

2. By convention, households are the final consumers, who are also allocated the benefits of government and NGOs, in what is termed as actual final consumption in SNA.

3. Statistical systems may have limitations in generating functional expenditure distributions with the data available. Classifications, which are relevant for decision-making, promote the search for a progressive refinement in reporting systems, which can be in parallel to the use of prorating through allocation keys. Separation is then made based on shares of human resources, utilisation and cost information, and so on. Also, a reporting strategy has been used that aggregates curativerehabilitative data. This aggregate also contains preventive components.

4. The characteristics of individual and collective consumption are explained in more detail in Chapter 3.

5. Two examples can be used to illustrate this challenge. A typical grouping, such as the diagnosticrelated groups (DRG), comprises several hundred hospital products embracing only a third of total hospital activity. Pharmaceuticals may number several thousand different entries, grouped in 14 different chapters when using the Anatomic Therapeutic Chemical (ATC) Classification. Therefore, the aggregation into groupings of health care functions may follow different paths.

6. In health accounts, tri-axiality involves the equivalence of consumption, provision, financing. The advantages of this approach include an optimal use of the data sources to ensure that neither double-counting nor omissions occur.

7. This follows SNA rules: "R\&D that does not provide an economic benefit to its owner should be treated as intermediate consumption" (SNA 2008, 10.103).

8. "When training is given by an employer to enhance the effectiveness of staff, the cost is treated as intermediate consumption" (SNA 2008, 1.54).

9. Instead of an episode, the tracking proposal is the contact or encounter. The difference is that a contact refers to each visit of the individual to the health system, whereas an episode can cover a series of contacts e.g. with various components of the health system in a single or multiple visit.

10. A specific description or "natural history of a disease" may exist per disease, which is adjusted in conjunction with the causal understanding of, in importance, the prevention and control of the disease. One example of such an adjustment concerns a neurological disease that was considered to be non-communicable until technological developments identified viral infections as the origin. It was no longer a genuine non-communicable disease, so its natural history of disease was modified.

11. In most countries each visit during chronic disease management is treated as a separate contact. 
12. Prevention is also delivered by MoP. However, for HC purposes, preventive care is reported by type of service. This is because most prevention initiated by the consumer is not properly recorded, while in most countries services delivered within an organised preventive programme are registered.

13. Information asymmetry between the health provider and the consumer is in most cases the main reason why consumers accept the therapeutic package indicated by the provider.

14. There are usually different types of separated records for each contact for care. When the person is discharged and sent home from the emergency department, the initial record is reported as an outpatient visit (including the emergency services, if the visit occurred there); when the patient is transferred to the hospital in the same establishment or to a different hospital, the service is recorded as inpatient. When a formal admission to inpatient care follows treatment in an emergency department, there will be two records: outpatient and inpatient. When a separation of the expenditure in such situations is not possible, then the whole of the expenditure should be counted as inpatient care.

15. It may be the case that the growing occurrence of non-face-to-face encounters will lead to a new specific MoP in the future.

16. Direct consumption can also be related to inpatient and day care, such as in the case of a second opinion consultation (see Figure 5.4).

17. In SHA 1.0 and SHA 2011, Ancillary services have the same connotation, referring to complementary services to health care. However, in the SNA ancillary refers to basic, routine services to support production activities that are required by all enterprises. When they are provided in-house, they are called ancillary activities, e.g. cleaning premises, running the staff payroll or providing the information technology infrastructure for the enterprise, etc.

18. Health care classes involve final consumption and include all cost components, e.g. e-medicine is expected to be included in the resources accounted for. E-medicine is the use, in the health system, of digital data - transmitted, stored and retrieved electronically - in support of health care, both at the local site and at a distance. Support to health care involves information-intensive means for management, for hospital care, day care, outpatient care, home-based care, the retailing of medical goods, immunisation \& other programmes, monitoring and evaluation, clinical information, surveillance and epidemiological work, know-how and knowledge, health education, cross-border trade, or the analysis and dissemination of medical data. It includes diverse services, e.g. tele-radiology, the transmission of radiographic images from one location to another for interpretation by a radiologist. It is most often used to allow rapid interpretation of emergency room, ICU and other emergency examinations after the hours of usual operation, at night and on weekends. The images are then often sent across time zones (Spain, Australia, India), with the receiving radiologist working his normal daylight hours. Tele-radiology can also be utilised to obtain a consultation with an expert or sub-specialist.

19. See earlier comment on a mental health night stay, which is usually also recorded as a day case.

20. As defined by the World Confederation for Physical Therapy: www.wcpt.org/node/27545.

21. Disabilities are not necessarily a permanent condition; for example, the sequelae of a stroke can be fully recovered after rehabilitation.

22. Rather than a pure classification based on the purpose of the goods and services, long-term care services also need to take into account some of the patient characteristics and level of dependency (severity-based). The labelling of the category also reflects this by the use of "long-term care (health)" rather than "long-term health care" to distinguish between services for beneficiaries suffering from certain conditions requiring treatment over a long period of time, but without a significant effect on their dependency, e.g. asthma, the majority of diabetes cases, etc. That said, disease complications can in turn lead to physical dependency. It has been estimated that $15 \%$ of the cost of treatment of diabetes in the United States is on nursing care due to kidney, retina and macula, neurologic and other complications (www.worlddiabetesday.org; www.idf.org).

23. In 2010, it was estimated that approximately 35 million people die every year from chronic life-limiting illnesses, of which less than $8 \%$ have access to LTC (Connor, 2010).

24. Long-term care needs increase significantly with age, with typically around $50 \%$ of the population aged over 65 requiring some form of long-term care (Bulletin Luxembourgeois des Questions Sociales, 2005).

25. An effort to collect systematic and comprehensive information for the European countries is presented in Salvador-Carulla and Gasca (2009). 
26. There is a complex relationship between disability (help with one or more ADL), frailty and comorbidity, which can be seen as distinct but inter-related concepts. As part of the Cardiovascular Health Study in 2001, a US community-dwelling population were classified as disabled or frail or as having co-morbidity. Of those categorised as frail and disabled, $79 \%$ also had co-morbidity. See Fried et al. (2001).

27. An example is Spain's Personal Autonomy and Dependent Care Law, which is based on the ICF model in theory but uses the ADL approach in the official assessment scale.

28. Inclusions involve a diversity of products, such as allergy/antihistamines, analgesics, antacids/ heartburn, anti smoking, anti fungal, cold and flu, eye drops, nutrition and diet (dietary supplements, laxatives). Excluded are components of personal care such as those stated in COICOP 12.1 and notably in the 12.1 .3 class with articles for personal hygiene: toilet soap, medicinal soap, cleansing oil and milk, shaving soap, shaving cream and foam, toothpaste, etc.; beauty products: sunbathing products, etc.; other products: sanitary towels, etc.

29. Essential medicines are medicines that address the priority health care requirements of a population. These medicines are selected through an evidence-based process with due regard to public health relevance, quality, safety, efficacy and comparative cost-effectiveness. The WHO Essential Drugs List was first published in 1977 and is updated every two years. It has proved to be a powerful tool for the promotion of primary health care by rationalising the selection and use of medicines as well as their cost (Hogerzeil, 2004).

30. The provision of an effective treatment in secondary prevention means not the provision itself, but all the measures supporting the provision in the system, notably measures such as the enforcement of regulations and quality assurance of the services. Pomey et al. (2000), pp. 339-344.

31. Environmental health components are related to regulatory enforcement and monitoring that concerns any agent posing an evidence-based immediate risk to humans, e.g. persistent organic pollutants and heavy metals, which are associated with air, water and food-borne diseases and transferred across borders and generations.

32. Safety involves all activities that seek to minimise or to eliminate hazardous conditions that can cause bodily injury. Occupational safety is concerned with risks in areas where people work: offices, manufacturing plants, farms, construction sites, and commercial and retail facilities. Public safety is concerned with hazards in the home, in travel and recreation, and in other situations that do not fall within the scope of occupational safety. Although safety involves a risk relationship that can be linked to health and to prevention, its uses are not universally included in that boundary but have to do with a collective nature in such a way that specialised principles, structures and social involvement generate a field that itself deals with each of those risks. Healthrelated management is thus restricted to components with an implicit mention of a health purpose.

33. An example of the health approach to these problems is found in the Global Status Report on Road Safety released by WHO in 2009.

34. The change from SHA 1.0 is considered to reflect a more accurate approach. Aggregation of types of preventive services allows a better taxonomy and flexible grouping. Among other taxonomic problems, several so-called "non-communicable" diseases have now been identified as communicable and are covered by vaccines that have been or are in the process of being produced.

35. Further breakdowns by population characteristics are discussed in Chapter 10, e.g. by population group by age and sex, by socioeconomic status, as well as by type of epidemiological group and by geographic area.

36. PM10 is used to describe airborne particulate matter with particles of 10 micrometers or less.

37. The approach by type of service is also considered better to identify opportunities to improve prevention in the field. Early case detection can also cover both communicable and noncommunicable diseases.

38. WHO (2002), WPRO WPR/RC53/10. EPHF 1.

39. WHO (2002), WPRO WPR/RC53/10. Mainly tasks associated with EPHF 2, Epidemiological surveillance/disease prevention and control.

40. WHO (2002), EPHF 2, Epidemiological surveillance/disease prevention and control and EPHF 8, Ensuring the quality of personal and population-based health services. WPRO WPR/RC53/10.

41. Comparability between countries would require a detailed set of metadata since advances in aetiology have shifted some diseases from one class to another, e.g. as in the case of neurological 
and cancer cases that are now identified as due to viral infections or in cases where the geographical distribution of certain communicable diseases has been modified due to environmental factors.

42. Governance is the careful and responsible management of something entrusted to one's care. In the context of health systems, it involves influencing policies and actions in all sectors that may affect the health of the population. The governance function therefore implies the ability to formulate strategic policy direction, to ensure good regulation and the tools for implementing it, and to provide the necessary intelligence on health system performance in order to ensure accountability and transparency. (WHO Europe)

43. SNA 2008 defines the value of an insurance service or insurance output in paragraph 6.185 as insurance output $=$ total premiums earned plus premiums supplements less adjusted claims incurred.

44. Chapter 9 discusses inputs by provider, the sum of which ought to be equivalent to this aggregate.

45. Modern medicine has also been called mainstream medicine (MM), allopathic medicine, conventional medicine, modern medicine, orthodox medicine, traditional medicine, Western medicine or clinical medicine. It involves the approach to health care practiced in developed nations, based on scientific data for diagnosing and treating disease; MM assumes that all physiologic and pathological phenomena can be explained in concrete terms; MM tools include non-human model systems, blind studies and statistical analysis to ensure reproducible results.

46. Examples of TCAM are: Acupuncture, Ayurveda, Chiropractics, Herbal Medicines, Homeopathy, Naturopathy, Osteopathy, Traditional African medicines (Muti, Yoruba Ifa), Traditional Chinese medicine (Tuina, Unani), Shiatsu, Mind-Body Intervention, Biologically-Based Therapy, Manipulative and body-based methods and Energy Therapy. The various therapies also include Qi Gong, Tai ji, Thermal therapy, Yoga, Magnetic Therapy, Reiki, Therapeutic Touch, Aromatherapy, Art/Msic therapy, Biofeedback, Hypnosis, Meditation, Mental imagery, Prayer and Spiritual healing.

47. For example, within chiropractics, out of the several hundred schools that claim to teach these practitioners, only 34 meet the minimum standards set out in the WHO Guidelines on Basic Training and Safety in Chiropractics (WHO, 2005c).

48. In South Africa a qualified registered health care practitioner must have achieved a minimum standard of training at an institution accredited by the relevant council set up by the Department of Health (DoH). Out of 190000 traditional health practitioners, there were about 3600 registered Allied Health Care Professionals in 2007 (Gqaleni et al., 2007).

49. So far, it is estimated that about 25000 complementary medicines, including traditional medicines, have been submitted for registration in South Africa. The global market for TCAM products has been estimated at USD 83 billion annually in 2008.

50. In the United States, for example, 83 million adults spent USD 33.9 billion out-of-pocket on TCAM in 2007 , representing $11.2 \%$ of total out-of-pocket expenditures on health care (NIH, 2009).

51. Countries in which this practice has been reported such as Indonesia, include an aggregate for Modern care and another for Traditional care. See BPS-Statistics Indonesia (2007, p. 133).

52. See for example the cases of the European Union (http://efsa.eu.int) and the WHO Regional Office for Europe (www.who.dk/Nutrition) and "Food and Health in Europe: A New Basis for Action", who.dk/ eprise/main/who/progs/FOS/Home. 


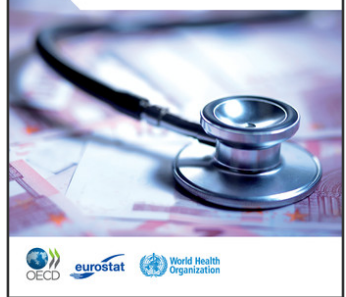

\section{From:}

A System of Health Accounts

2011 Edition

Access the complete publication at:

https://doi.org/10.1787/9789264116016-en

\section{Please cite this chapter as:}

OECD/World Health Organization/Eurostat (2011), "Classification of Health Care Functions (ICHA-HC)", in A System of Health Accounts: 2011 Edition, OECD Publishing, Paris.

DOI: https://doi.org/10.1787/9789264116016-7-en

This work is published under the responsibility of the Secretary-General of the OECD. The opinions expressed and arguments employed herein do not necessarily reflect the official views of OECD member countries.

This document and any map included herein are without prejudice to the status of or sovereignty over any territory, to the delimitation of international frontiers and boundaries and to the name of any territory, city or area.

You can copy, download or print OECD content for your own use, and you can include excerpts from OECD publications, databases and multimedia products in your own documents, presentations, blogs, websites and teaching materials, provided that suitable acknowledgment of OECD as source and copyright owner is given. All requests for public or commercial use and translation rights should be submitted to rights@oecd.org. Requests for permission to photocopy portions of this material for public or commercial use shall be addressed directly to the Copyright Clearance Center (CCC) at info@copyright.com or the Centre français d'exploitation du droit de copie (CFC) at contact@cfcopies.com. 